\title{
Pseudouridine-free Ribosome Exhibits Distinct Inter-subunit Movements
}

\author{
Yu Zhao ${ }^{1}$, Jay Rai ${ }^{1}$, Hongguo $\mathrm{Yu}^{2}$ and Hong $\mathrm{Li}^{1,3 *}$ \\ ${ }^{1}$ Institute of Molecular Biophysics, ${ }^{2}$ Biological Science Department, ${ }^{3}$ Department \\ of Chemistry and Biochemistry, Florida State University, Tallahassee, FL 32306, \\ USA.
}

${ }^{*}$ Corresponding author: hong.li@fsu.edu 


\section{Abstract}

Pseudouridine, the most abundant form of RNA modification, is known to play important roles in ribosome function. Mutations in human DKC1, the pseudouridine synthase responsible for catalyzing the ribosome RNA modification, cause translation deficiencies and are associated with a complex cancer predisposition. The structural basis for how pseudouridine impacts ribosome function remains uncharacterized. Here we report electron cryomicroscopy structures of a fully modified and a pseudouridine-free ribosome from Saccharomyces cerevisiae. In the modified ribosome, the rearranged N1 atom of pseudouridine is observed to stabilize key functional motifs by establishing predominately water-mediated close contacts with the phosphate backbone. The pseudouridine-free ribosome, however, is devoid of such interactions and displays conformations reflective of abnormal inter-subunit movements. The erroneous motions of the pseudouridine-free ribosome may explain its observed deficiencies in translation. 


\section{Introduction}

Among all RNA that are known to be chemically modified, ribosomal RNA (rRNA) is only next to transfer RNA (tRNA) in modification abundance. Roughly 2\% rRNA nucleotides contain 12 of the 140 known types of RNA modifications (Sharma and Lafontaine, 2015; Sloan et al., 2017). These modifications are believed to 1) impact rRNA stability (Gigova et al., 2014; Natchiar et al., 2017; Noon et al., 1998; Polikanov et al., 2015); 2) fine-tune ribosome function through modulating RNA-RNA and RNA-protein interactions (Natchiar et al., 2017; Polikanov et al., 2015); 3) prevent or promote ligand binding (Jack et al., 2011; Jiang et al., 2016; Natchiar et al., 2017); and 4) regulate ribosome assembly (Ghalei et al., 2017; Leppik et al., 2017; Liang et al., 2007, 2009b; Liu et al., 2008). Partial modification of rRNA nucleotides has recently been observed that can contribute to ribosome heterogeneity (Simsek et al., 2017). Both the diversity and the heterogeneity of modifications are believed to contribute to selective translation of specific mRNAs, adding a new layer of translational control of gene expression. Despite the rich biochemical and genetic evidence, the exact roles of the chemical modifications on rRNA on ribosome structure, however, have not been observed.

The most abundant modifications of rRNA are 2'-O-methylation and uridine isomerization (pseudouridylation), both of which are installed by small nucleolar ribonucleoparticles (snoRNPs) (Decatur and Fournier, 2003; Fatica and Tollervey, 2002; Maxwell and Fournier, 1995; Yu and Meier, 2014). The box C/D snoRNPs are responsible for site-specific addition of 2'-O-methyl groups at 80-100 sites in rRNA whereas the box H/ ACA snoRNPs are responsible for isomerization 
of similar numbers of uridine. Each snoRNP is comprised of a catalytic subunit (fibrillarin as the methyltransferase and Cbf5p as the pseudouridine synthase in yeast, respectively), three accessory proteins, and a snoRNA capable of targeting the modification site(s) through base pairing (Decatur and Fournier, 2003; Liang and Li, 2011; Maxwell and Fournier, 1995; Watkins and Bohnsack, 2012). The effect of individual or a subset of snoRNP-mediated modification on cellular functions was previously studied by selectively removal of one or a small number of snoRNAs in yeast.(Babaian et al., 2020; Baxter-Roshek et al., 2007; King et al., 2003; Liang et al., 2007, 2009b; Piekna-Przybylska et al., 2008) Definitive defects in translation were observed in these yeast cells that can be attributed in part to changes in ribosome structures detected by dimethyl sulfate probing or the change in translation rate (Liang et al., 2007; Piekna-Przybylska et al., 2008).

In human, mutations or abnormal level of snoRNPs are associated with diseases ranging from reduced immunity against pathogens(Tiku et al., 2018) to predisposition to cancer (Heiss et al., 1998). Note that several special box C/D snoRNPs (U3, U14, U8) are essential components required for rRNA processing(Dragon et al., 2002) or as part of the telomerase ribonucleoprotein complex (Mitchell et al., 1999). which raises the question if a lack of chemical modification is the direct causes of these diseases. Understanding the snoRNPsassociated malignancy, therefore, requires dissecting the molecular mechanism of the molecules with which snoRNPs act upon or are associated under these conditions. Previously, mutation of the catalytic domain of Cbf5p, Asp95 in yeast, and $D k c 1^{m}$ in mammals, was shown to cause translation defects, most prominently in regulation of the IRES (internal ribosome entry site)-mediated, CAP- 
independent, translation without affecting the overall level of other genes (Bellodi et al., 2010; Jack et al., 2011; Yoon et al., 2006). This suggests a specific effect on ribosome in absence of pseudouridylation. Mutation of Cbf5 in human including $D k c 1^{m}$ is associated with Dyskeratosis Congenita (DC) that also has translational defects (Bellodi et al., 2010; Yoon et al., 2006). These findings underscore a direct impact of chemical modifications on ribosome-associated diseases.

Ribosome is a complicated molecular device visiting multiple states even when not translating and driven by thermal forces (Cornish et al., 2008; Frank and Gonzalez, 2010; Moore, 2012). Conformational dynamics lies at the heart of ribosome function optimally tuned for catalytic efficiency as well as translation fidelity. Translational factors and tRNA including their charge status promote conformational transitions required for the cyclic processes of initiation, elongation, and termination (Korostelev et al., 2008). Not surprisingly, factors that alter ribosome dynamics are also associated with translational deficiency (Sengupta et al., 2019; Sulima et al., 2014). Thus, characterization of these dynamic states provides a necessary biophysical basis for understanding ribosome function and associated diseases (Frank, 2016). While many of the conformational transitions, especially those of the bacterial ribosome, has been thoroughly characterized (Schmeing and Ramakrishnan, 2009). how chemical modifications influence these processes, and in turn, ribosome function, remain uncharacterized owing to the lack of structures of unmodified ribosome.

Here, we analyzed structures of vacant ribosomes isolated from yeast strains harboring the nop1-D243A or the $c b f 5-\mathrm{D} 95 \mathrm{~A}$ mutation that is predicted to 
disrupt the chemical modification reactions catalyzed by fibrillarin and Cbf5p, respectively. We showed that while the nop1-D243A was not sufficient to remove 2'-O-methylation, the cbf5-D95A mutation resulted in ribosomes without pseudouridylation. Structure determination and comparison of the fully modified and the pseudouridine-free ribosome isolated from the nop $1-\mathrm{D} 243 \mathrm{~A}(2.57 \AA-2.72 \AA)$ or the $c b f 5$-D95A $(2.89 \AA-3.03 \AA)$ cells revealed a profound link between rRNA pseudouridylation and ribosome dynamics.

\section{Results}

Cell Growth and Polysome Profile Defects in nop1-D243A and cbf5-D95A Cells

Owing to the essentiality of fibrillarin and Cbf5p, we created yeast strains containing fibrillarin or Cbf5p mutants that lack the predicted catalytical residues. Fibrillarin belongs to the well-conserved 2'-O-methyltransferase family that include bacterial RrmJ(FtsJ) methyltransferase and the vaccinia virus VP39 methyltransferase whose catalytic residues had been identified by a combination of structural, bioinformatic and in vitro studies (Feder et al., 2003; Hager et al., 2002; Hodel et al., 1996) to contain a K-D-K-E tetrad. The tetrad corresponds to Lys150-Asp243-Lys272-Glu310 in yeast fibrillarin where Lys272 and Glu310 are believed to position the target RNA nucleotide while Lys150 and Asp243 play a catalytic role in the methyl transfer reaction. In addition, Glu198, similar to Asp83 of RrmJ, forms a close contact with the methyl donor, S-adenosyl-L-methionine (SAM), and is believed to be critical for SAM binding. Individual mutations of the 
tetrad residues, especially the aspartate residue, in RrmJ are detrimental to methylation both in vitro and in cells (Hager et al., 2002). Mutation of the aspartate in an archaeal fibrillarin also severely reduced in vitro methylation activity(Aittaleb et al., 2004). We, therefore, created the yeast strain whose genomic nop1 encodes Asp243Ala (nop1-D243A). The mutation was confirmed by sequencing the PCR-amplified nop1 locus from the genomic DNA of the strain (Supplementary Figure 1).

Similarly, the catalytic residues in Cbf5p were identified by its homology to the bacterial TruB pseudouridylase and by in vitro activity assays (Liang et al., 2009a). Critical to the isomerization reaction is a strictly conserved aspartate in all TruB family of pseudourylases (Liang et al., 2009a; Spedaliere et al., 2004) that corresponds to Asp95 of Cbf5p. We created a yeast strain whose genomic cbf5 encodes Asp95Ala mutation (cbf5-D95A) and verified the strain by sequencing (Supplementary Figure 1). A similar strain was constructed previously with an episomal plasmid in cbf5-deletion cells, which resulted in viable cells that lack rRNA pseudouridylation (Jack et al., 2011; Zebarjadian et al., 1999).

Growth of the two mutant strains was assessed at three temperatures. In comparison with the wild-type, both strains exhibit severe growth deficiency at temperatures ranging from $25^{\circ} \mathrm{C}-37^{\circ} \mathrm{C}$ (Figure 1). While the phenotype observed for $c b f 5-\mathrm{D} 95 \mathrm{~A}$ is similar to that previously shown in the strain carrying D95A on an episomal plasmid, that observed for nop1-D243A is novel and suggests an important role of Asp243 of fibrillarin in cell growth. 
To access the impact of the nop1-D243A and cbf5-D95A mutations in ribosome assembly, we performed sucrose density gradient centrifugation and compared polysome profiles between the wild-type and the two mutant cells grown in both normal and glucose depleted media. In comparison with the wild-type cells, there is an elevated level of free $40 \mathrm{~S}$ in the nop1-D243A and that of free $60 \mathrm{~S}$ in the cbf5D95A cells, respectively, suggesting definitive but different defects in ribosome maturation in the mutant cells (Figure 1B). Despite so, both cells were able to produce sufficient 80 in supporting cellular functions (Figure 1B).

\section{A Fully Modified and a Pseudouridine-free Ribosome}

We next examined the structures of the ribosome purified from the nop1D243A and cbf5-D95A cells. We took advantage of the fact that slowly growing yeast accumulates inactive but homogenous ribosomes (Waldron et al., 1977) and purified them by two different methods to ensure consistent isolation of intact $80 S$ from both strains (Materials and Methods) (Ben-Shem et al., 2011; Ben-Shem et al., 2010). We performed single particle analysis of the ribosomes isolated from the nop1-D243A and the cbf5-D95A cells, respectively. Initial classification and reconstruction revealed that a large majority of ribosome particles from either strain isolated by the affinity-based method are bound with the suppressor of target of Myb protein 1 (Stm1) (Figure 2), a known hibernation factor, that is similarly found in the inactive yeast 80 S crystal structures (Ben-Shem et al., 2011; Ben-Shem et al., 2010). This form of the ribosome was used in comparative studies between the two ribosomes. 3D classification and focused refinement resulted in 
an overall resolution of 2.57-2.72 $\AA$ for the nop1-D243A ribosome (Supplementary Figure 2) and 2.89-3.03 $\AA$ for the cbf5-D95A ribosome (Supplementary Figure 3), respectively.

The electron potential density readily revealed that, despite the known catalytic role of Asp243 of fibrillarin in 2'-O-methylation, the nop1-D243A ribosome still carries 2'-O-methylation at all positions targeted by snoRNPs (Supplementary Figure 4 \& Table S1). Analysis of water molecules surrounding uridine showed that nop1-D243A ribosome display an interaction pattern consistent with the presence of pseudouridine at the predicted positions, as expected (Supplementary Figure 4). In contrast, the cbf5-D95A ribosome displays an interaction pattern indictive of a lack of pseudouridylation (Supplementary Figure 4 \& Table S1), supporting the known catalytic role of Asp95 in isomerization. These structural observations suggest that nop1-D243A mutation is insufficient to remove 2'-O-methylation while $c b f 5-\mathrm{D} 95 \mathrm{~A}$ mutation substantially reduced pseudouridylation. While the reason for the growth phenotype of nop1D243A yeast strain is unclear, the high resolution of this ribosome provided us with an opportunity to model and analyze fully modified yeast ribosome (Figure 2). We were able to model 40 of the 45 pseudouridine, 54 of the 552 '-O-methylation, and 11 of the 13 base modification nucleotides on the nop1-D143A ribosome (Supplementary Table 1). The structure of cbf5-D95A ribosome structure, on the other hand, allowed us to examine the structural features of the pseudouridinefree yeast ribosome (Figure 2) that was modeled with the same modified nucleotides except for pseudouridine (Supplementary Table 1). 


\section{Distinct Motions of Ribosome with and without Pseudouridylation}

We next analyzed and compared the structural conformations present in the fully modified and the pseudouridine-free ribosome that are bound with Stm1. For the best particles resulted from extensive selection, we performed 3D classification using a mask around the head of 405 followed by reconstruction. This procedure allowed us to examine conformationally distinct structures present in a single sample. Seven structures were obtained from the nop1-D243A ribosome with average resolutions of $2.8 \AA$ to $3.2 \AA$ (Figure 3A). Six structures resulted from the $c b f 5-D 95 \mathrm{~A}$ ribosome, albeit at lower resolutions of $4.3 \AA$ to $5.8 \AA$ (Figure 3B). To compare the conformations among the distinct ribosome structures, we computed and plotted the two rotation axes previously described as ribosome ratcheting and swiveling, respectively (Ling and Ermolenko, 2016). For a given pair of structures, we superimposed the densities of their large subunits onto the same 60S reference density and computed the angle and location of the transformation axis that brings one small subunit body to the other (ratcheting). We then aligned the small subunit bodies of both structures to the same reference body density and computed the angle and location of the transformation axis that brings one small subunit head to the other (swiveling). We also computed the same parameters for previously characterized ribosome conformations for comparison (Supplementary Figure 5).

Structure I of nop1-D243A ribosome $\left(\mathrm{I}_{\mathrm{f}}\right)$, which represents $8 \%$ of the total particles, closely matches the fully non-rotated conformation when bound with two tRNA and a model mRNA molecules (PDB ID: 3J78) (Svidritskiy et al., 2014) 
(Figure 3A). Therefore, we compared the six remaining structures with respect to $\mathrm{I}_{\mathrm{f}}$. The remaining structures resemble a series of pre-translocation intermediates with ratcheting angles ranging $3^{\circ}-9^{\circ}$ and swiveling angles ranging $7^{\circ}-13^{\circ}$. None of these, however, resembles the conformation of the fully rotated conformation (PDB ID: 3J77) captured when bound with one tRNA at its P/E site with $\sim 11^{\circ}$ ratcheting and near $0^{\circ}$ swiveling (Svidritskiy et al., 2014). Among the intermediates, structures $\mathrm{II}_{\mathrm{f}}$ and $\mathrm{III}_{\mathrm{f}}$ that together represent $55 \%$ of the total particles, resemble the two conformations captured in the crystal structures (PDB IDs: 4V88 and 4V7R) (Ben-Shem et al., 2011; Ben-Shem et al., 2010) based on the body rotation. These two conformations differ in ratcheting by $\sim 5^{\circ}$ and swiveling by $\sim 7^{\circ}$ (Supplementary Figure 5). Interestingly, structures $\mathrm{IV}_{\mathrm{f}}, \mathrm{VI}_{\mathrm{f}}$, and $\mathrm{VII}_{\mathrm{f}}$ that together represent $29 \%$ of the particles, are highly similar among themselves and resemble the pre-translocation intermediate observed when the Taura Syndrome Virus IRES, eEF2-GDP are bound to ribosome with a fully rotated 40S body (PDB ID: 5JUO) (Abeyrathne et al., 2016) (Supplementary Figure 5). Structure $\mathrm{V}_{\mathrm{f}}$, that comprises $8 \%$ of the particles has a nearly non-rotated body but swiveled head of 40S. Strikingly, all rotations of the nop1-D243A ribosome are anchored on two sites within the $40 S$ subunit, one for ratcheting and one for swiveling, respectively, suggesting that nop1-D243A ribosome is shaped to support these intrinsic motions (Figure 3).

3D classification of the $c b f 5-D 95 \mathrm{~A}$ ribosome resulted in six structures. Unlike nop1-D243A ribosome, the cbf5-D95A ribosome do not include the nonrotated conformation. Like nop1-D243A ribosome, no cbf5-D95A ribosome 
conformation matches the fully rotated conformation (3J77). Therefore, the cbf5D95A ribosome was compared to the non-rotated structure $\mathrm{I}_{\mathrm{f}}$ of nop1-D243A ribosome. With exception to structures $\mathrm{II}_{\mathrm{c}}$ and $\mathrm{III}_{\mathrm{c}}$ that together make up $43 \%$ of the particles and somewhat resemble the crystal structure $4 \mathrm{~V} 7 \mathrm{R}$, none matches known ribosome conformations we examined (Supplementary Figure 5). Furthermore, these rotations, especially ratcheting, do not anchor on single sites within ribosome unlike those of the nop1-D243A ribosome (Figure 3B).

To examine the major modes of motion among all particles, we performed multi-body analysis on ribosome from each cell by dividing ribosome into three rigid bodies: the head, the body, and the large subunit. The resulting top three normal mode motions from each ribosome were compared in terms of the direction and the range of the motions. While the major motion of nop1-D243A ribosome is that the head and body of $40 S$ rotate in sync with respect to $60 S$ (Supplementary Figure S6 \& Supplementary data movie 1), that of cbf5-D95A ribosome comprises of independent rotations of the head and body of $40 \mathrm{~S}$ with respect to 60S in different directions (Supplementary Figure S6 \& Supplementary data movie 2). The next two major eigen vectors also differ in the degree and direction of motions substantially from those of the nop1-D243A ribosome (Supplementary Figure S6 \& Supplementary data movies 3-6). This result further supports that the conformational dynamics differ largely between the fully modified and the pseudouridine-free ribosome. 
Mapping the positions of modified nucleotides onto the refined yeast 605 structure model readily revealed that modifications are clustered within three functional centers: the peptidyl transferase center (PTC), the inter-subunit bridge (ISB) and the A-site finger (ASF) (King et al., 2003). Notably, biochemical analyses showed that mutations in proteins closely associated with PTC, rpL10p and rpL3p (Meskauskas and Dinman, 2008; Sulima et al., 2014), had profound effects on ribosome dynamics and thus translation fidelity. To illustrate how these modification clusters are linked to the mechanics of ribosome motion, we computed pair-wise displacements of the $25 \mathrm{~S}$ rRNA nucleotides between the nonrotated and the rotated structures when their $40 \mathrm{~S}$ subunits are superimposed (Figure 4A) and mapped the sites of psedouridylation and 2'-O-methylation on the nucleotide-wise displacement plot. Strikingly, pseudouridine clusters associated with PTC and ISB largely coincide with their minimal motion while the pseudouridine cluster associated with ASF experiences a significant translocation. This result suggests a motion-dependent distribution of pseudouridine on 60S.

Distribution of pseudouridine on the $18 \mathrm{~S}$ is more scattered and does not seem to be correlated with the rotated-to-non-rotated displacement of nucleotides (Supplementary Figure 7). On the other hand, when modification sites are mapped on to the nucleotide-wise displacement plot from the swivel to the non-swivel 18S structures, it is clear that helix $44(\mathrm{H} 44)$ is stationary, although it completely lacks chemical modifications. On the other hand, H44 interacts closely with the conserved helix 69 (H69) of ISB that contains a pseudouridine cluster (Supplementary Figure 7), suggesting that modifications on H69 may also impact head movement. 
Examination of interactions mediated by pseudouridine in the nop1-D243A ribosome structure indicates that pseudouridine primarily stabilizes intra-strand interactions while also participate in other interactions. The density peak near the N1 atoms of a large number of pseudouridine that likely represents a water molecule is observed to be within hydrogen bond distance to the non-bridging oxygen of phosphate backbone of either the same or the preceding nucleotide (Figure 4 \& Supplementary Figure 4). The same features are absent in the $c b f 5$ D95A ribosome (Supplementary Figure 8). The intra-strand stabilization helps to maintain the integrity of the pseudouridine-rich helix 38a in ASF during translocation (Figure 4). Within ISB, we observed the same type of intra-strand interactions such as those in helix 68 (H68) as well as base-triple interactions such as those among $\Psi 2133$, A2147 of H68 and A896 of helix 33 (H33) (Figure 4C). The pseudouridine-stabilized ISB interacts with the stationary H44 of the 40S, which could facilitate head swivel (Supplementary Figure 7).

Interestingly, pseudouridine-mediated interactions within PTC coincide with the large subunit proteins previously shown to impact ribosome dynamics (Meskauskas and Dinman, 2008; Sulima et al., 2014). The P site loop of rpL10p, 102-112, resides near a pair of pseudouridine, $\Psi 2826$ and $\Psi 2865$ of helix 89 (H89), that participate in intra-strand hydrogen bonds (Figure 4C). The highly charged N-terminus and a long loop (236-260) of rpL3p sandwich another pair of PTC pseudouridine, $\Psi 2880$ and $\Psi 2944$ of helix 90 (H90), that forms cross-strand interactions uniquely stabilized by pseudouridine (Figure 4C). These protein 
elements may further strengthen or counterbalance those established by pseudouridine at PTC as ribosome undergoes the non-rotated to the rotated transitions.

\section{Discussions}

To examine the functional roles of rRNA modifications, we constructed yeast strains harboring either the nop1-D243A or the $c b f 5-\mathrm{D} 95 \mathrm{~A}$ genomic mutation that is predicted to inactivate the respective modification enzymes while maintaining proper snoRNP assembly. We showed by structural biology methods that while the $80 S$ ribosome from the nop1-D243A yeast contains fully modified rRNA, which indicates an active fibrillarin D243A, that from the cbf5-D95A yeast lacks pseudouridine. We compared structures, both global and local, as well as the dynamics between the nop1-D243A and the cbf5-D95A ribosome. While local structural environments around modified sites are similar at the current structure resolutions, the overall structural dynamics of the three major domains of 805 exhibits large differences between the fully modified and the pseudouridine-free $80 S$.

A large body of literature has eluted to a critical role of rRNA pseudouridylation in ribosome maturation and translation. Selective removal of individual or a subset of pseudouridine (Babaian et al., 2020; King et al., 2003; Liang et al., 2007; Piekna-Przybylska et al., 2008) caused an accumulatively negative effect on cell growth. These cells showed defective rRNA processing and altered ribosome profiles. The use of dual plasmid luciferase assay permitted 
direct assessment of translation in yeast cells (Ghalei et al., 2017; Rakauskaite et al., 2011). In the cbf5-D95A cell where rRNA pseudouridylation was abolished, decreased fidelity and defects in initiations were observed (Jack et al., 2011), suggesting a change of ribosome structural properties. Interestingly, DKC1 mutations in both mouse cells and the Dyskeratosis Congenita patient cells differentially impact the CAP-dependent and the IRES-mediated translation.(Bellodi et al., 2010; Yoon et al., 2006) Our structural analysis of the fully modified and the pseudouridine-free ribosome provides a structure-based explanation for the observed translation defects in cells. We believe that the three pseudouridine clusters within the large subunit stabilize the key regions that are necessary for proper inter-subunit movements. In absence of pseudouridine, ribosome losses the ability to drive the motions accurately.

Our analysis of the pseudouridine-free ribosome dynamics does not eliminate other possible deleterious effects in these ribosome such as changes in ligand binding. These effects, when combined with altered ribosome movements, whether directly or indirectly, can have differential impacts on different translation processes. $\Psi 2919$, for instance, base pairs with the $3^{\prime}$ end of A site tRNA and the loss of its modifying snoRNA, snR10, led to reduced rate of translation (King et al., 2003). Similarly, loss of snoRNAs that guide pseudouridylation of those on H38 of ASF exhibited increased sensitivity to several antibiotics binding even though these antibiotics do not directly bind to ASF (Piekna-Przybylska et al.,

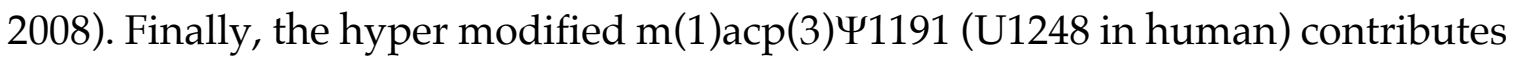
to $\mathrm{P}$ site decoding interactions and its loss reduced the level as well as the activity 
of ribosome in yeast(Babaian et al., 2020; Liang et al., 2009b). In human, loss of the hypo-modification of $\mathrm{U} 1248$ is a prominent feature in multiple forms of cancer(Babaian et al., 2020).

The Stm1-bound ribosome represents an inactive form of the ribosome that accumulates under cell stress or carbon depletion (Ashe et al., 2000). The observed structural properties of the Stm1-bound ribosome do not reflect all conformations ribosome visits throughout its functional cycle. However, it is a landing-pad for yeast ribosome structural studies owing to its sample homogeneity, and has been discovered to mimic the rotated, mRNA-bound form of the $80 \mathrm{~S}$. Thus, the modes of ribosome motion can be representative of those possible in actively translating ribosome. Though this study focuses on structural comparison of a single ribosome form, similar differences are likely to be observed between the fully modified and the pseudouridine-free ribosome in other states, if these ribosome states are to be assembled and analyzed structurally in the future.

\section{Experimental Methods}

\section{Construction of Yeast Strains}

Saccharomyces cerevisiae haploid strain BY4741 was used as the genetic background to create the mutant strains by applying the Polymerase Chain Reaction (PCR) based method (Gardner and Jaspersen, 2014). In brief, a genespecific mutation module was PCR amplified using pFA6a-3HA-kanMX6a

plasmid as template and was later transformed into the wild-type cells. Transformants were selected with geneticin (G418). Correct mutation was 
confirmed by colony PCR and DNA sequencing. For both nop1-D243A and cbf5D95A, the aspartic acid was mutated to alanine by changing the codon from GAT to GCT.

Growth phenotype of mutant strains was characterized by serial dilution and spotting assay analysis. For polysome profile analysis, cells were grown to log phase (OD600 0.4-0.6) in 200ml of liquid yeast peptone dextrose (YPD) before being shifted to YPD or yeast peptone (YP) for 10 minuets. Cells were harvested at $5000 \mathrm{rpm}$ for 20 minutes in presence of $100 \mu \mathrm{g} / \mathrm{ml}$ of cycloheximide (CHX) followed by washing and resuspending with profiling buffer $(10 \mathrm{mM}$ Tris- $\mathrm{HCl}$ pH7.5, 100mM KCl, 5mM $\mathrm{MgCl}_{2}, 6 \mathrm{mM} \beta$-mercaptoethanol ( $\beta$-ME), $100 \mu \mathrm{g} / \mathrm{ml}$ CHX). Cells were broken by glass bead beating for six sets of 20sec-vertexing with 40sec-intervals at $4{ }^{\circ} \mathrm{C}$. Lysates were cleared by centrifugation at 16000rpm in a tabletop centrifuge for 20 minutes at $4{ }^{\circ} \mathrm{C}$. 9-11 UV 260nm units of the cleared lysate were loaded onto a 10\%-50\% sucrose gradient and centrifuged for 2.5 hours in a sw41Ti rotor at $4{ }^{\circ} \mathrm{C}$. Fifty $200 \mu$ l-fractions were manually taken from top to bottom of the gradient. UV absorbance at $254 \mathrm{~nm}$ was measured for each fraction and plotted against volume to generate the polysome profiles (Figure 1).

\section{Purification of Hibernating Ribosomes}

Inactive ribosomes were purified using the standard sucrose density gradient ultracentrifugation method. We used the same S. cervisiae BY4741 strains 
harboring either nop1-D243A or cbf5-D95A that also contain a streptavidin-binding peptide tag on Kre33p, TAP tag on Pwp2p. Yeast cells were grown to an optical density (OD) of 12-16 to accumulate inactive ribosome. The cells were harvested and lysed by a standard cryogenic grinding method. Broken cells were thawed on ice and resuspended in a lysis buffer and cleared by centrifugation at $10000 \mathrm{~g}$ for 10 min at $4{ }^{\circ} \mathrm{C}$. The resulting supernatant was loaded on top of $10 \%-50 \%$ sucrose gradients and then centrifuged at $28000 \mathrm{rpm}$ in a sw28 rotor for 2.5 hours at $4{ }^{\circ} \mathrm{C}$. Fifty fractions at $800 \mu$ l volume were taken from the top to bottom using pipette. The UV (254 nm) absorbance of each fraction was measured using Nanodrop2000. The fractions corresponding to the 805 peak fractions were pooled and pelleted for 1 hour at $436000 \mathrm{~g}$ and $4^{\circ} \mathrm{C}$ in a TLA-100 rotor. Pelleted $80 \mathrm{~S}$ were resuspended in the grid preparation buffer and kept on ice until cryo-EM grid preparation. Preliminary reconstruction indicated excellent nop1-D243A ribosome but heterogenous $c b f 5-\mathrm{D} 95 \mathrm{~A}$ particles purified by this method.

We also purified ribosome by an affinity method in a magnesiumcontaining buffer that favors binding of the inactive 805 to an IgG column (Rai et al., 2021; Scaiola et al., 2018). The cells were grown similarly as described above to accumulate inactive ribosome and lysed. The resuspended supernatant was incubated with IgG Sepharose beads (GE healthcare) for binding and followed by incubation with a TEV protease treatment mixture. The ribosome eluted from the IgG beads is in good condition for both strains and was used in cryoEM grid preparation in 25mM HEPES-Na pH 7.5, $100 \mathrm{mM} \mathrm{NaCl}, 10 \mathrm{mM} \mathrm{MgCl}$ and $1 \mathrm{mM}$ dithiothreitol (DTT) and reconstruction. 
Cryo-EM Sample Preparation, Cryo-EM Data Collection and Analysis

$5 \mu \mathrm{l}$ of each ribosome sample at 2-4 units of UV $260 \mathrm{~nm}$ absorbance was applied to a plasma cleaned 300 mesh UltraAufoil 1.2/1.3 grid (Quantifoil, Germany). The grids were blotted for $2-3 \mathrm{sec}$ at $8^{\circ} \mathrm{C}$ in $100 \%$ humidity (blot force 1) and plunged into liquefied ethane cooled with liquid nitrogen using Vitrobot MK IV (FEI, Hillsboro OR). The grids were transferred into a Titan Krios (Thermo Fisher) electron microscope equipped with a K3 detector (Gatan) that operated at $300 \mathrm{kV}$. Micrographs were collected in a movie-mode (frames) using Leginon(Suloway et al., 2005) with a total dose of $60 \mathrm{e}^{-} / \AA^{2}$ spreading over 70 to 74 frames at a nominal magnification of $81,000 \mathrm{X}$ in counting mode to a calibrated pixel size of $1.074 \AA$ / pixel and with a defocus ranging of -1.3 to -2.5 microns. Micrograph was inspected manually and the micrographs showing poor ice, too much drift, bad sample quality, empty hole or signs of astigmatism were discarded. The FSC was estimated at 0.143 -cutoff and the local resolution was estimated using ResMap (Kucukelbir et al., 2014).

For the nop1-D243A ribosome, a total of 6,460 micrographs were collected, among which, 4,962 micrographs were selected for further processing (Supplementary Figure 2). Frame alignment and dose compensation were carried out with Motincor2 (Zheng et al., 2017) and the Contrast Transfer Function (CTF) parameters were estimated with Gctf (Zhang, 2016) using a wrapper provided in Relion 3.1 (Zivanov et al., 2018). In total, 695,940 particles were picked using the 
LoG-based autopicking (bin by 4) and divided into two halves (432,895 and $264,100)$ to perform 2D class averaging and initial 3D classifications. 459,726 particles were further selected based on 2D classes by eliminating bad classes. The initial orientations were obtained via 3D classifications using an $80 \AA$ low-pass filtered 805 map. Particles were further eliminated from the classes resulted in poorly defined maps to a final set of 326,455 particles. The resulting particles were re-extracted without binning and refined to an overall resolution of $3.24 \AA$. After performing the multiple rounds of CTF refinement as implemented in Relion 3.1, the resolution could be improved to $2.95 \AA$. Additional classification without alignment was performed to further eliminate particles to 297,800 that were rerefined followed by particle polishing to an overall resolution to $2.84 \AA$. The 2.84 Å-resolution map showed excellent quality for 605 but diffused features for $40 S$. Focused refinement was subsequently applied to obtain best features for both two subunits. To obtain 605 density, 3D classification without alignment was performed with a customized mask around 60S. The classes showing good 605 density were pooled and re-refined using the 605 mask to the final overall resolution of $2.57 \AA$ (0.143 FSC). To obtain 40 density, 3D classification without alignment was performed by applying customize mask around 40S. The classes showing good $40 \mathrm{~S}$ density were $(289,345$ particles $)$ pooled and re-refined using the $40 S$ mask to a final overall resolution of $2.76 \AA$ A. We further applied the similar focused refinement procedure on the head and body of the small subunit, respectively leading to final overall resolutions of $2.72 \AA$ for both head and body (0.143 FSC). To sort out Stm1-containing ribosome, particles with good 40S density were classified without alignment using a spherical mask around the mRNA entry channel, leading to 209,566 particles that resulted in good Stm1 density. The Stm1- 
containing particle set was used in ribosome conformational analysis by 3D classification and multi-body analysis as implemented in Relion 3.1 (Supplementary Figure 2).

For the Cbf5-D95A sample, a total of 6,358 micrographs were collected, among which 5,800 micrographs were selected for further processing. Frame alignment, dose compensation, CTF-estimation and particle picking were carried out as described above (Supplementary Figure 3). The total 726,857 particles were prepared into a stack that was exported to cryoSPARC (Punjani et al., 2017). Multiple rounds of 2D classification and selection resulted in 462,537 good particles. Heterogenous refinement led to five classes among which three were pooled (404,065 particles) and refined in RELION 3.1 leading to a map with wellresolved 605 but diffused 40 S density features with an overall resolution of $3.17 \AA$. The per-particle CTF refinement followed by focus refinement using the 3D custom masks around $60 S$ region and 40S, respectively leading to $2.89 \AA$ and 3.03 $\AA$ for the 605 and 40S, respectively. Additional focused refinement on the head and body of $40 S$ subunit using 3D customized masks yielded the resolution of 3.03 $\AA$ and $2.99 \AA$ for the head and body, respectively. To clearly identify Stm1containing ribosome, the particles with the best 405 subunit resolution were classified without alignment into five classes. The predominant class $(239,637$ particles) was further refined using a custom mask on a 405 subunit resulted in a resolution of $3.36 \AA$ A $3 \mathrm{D}$ classification without alignment using a spherical mask around the mRNA entry channel identified two major classes that showed clear Stm1 density and were pooled together for subsequent conformational analysis (Supplementary Figure 3). 


\section{Model building}

The X-ray crystal structure of Stm1-bound 80S (PDB ID: 4V88) was used as the initial structure for model building. The $4 \mathrm{~V} 88$ structure was fit into a composite cryo-EM density map comprising those for the 605 , head and body of $40 S$ subunits. Manual examination and adjustment of the entire structure was carried out before initial rounds of real-space refinement as implemented in PHENIX(Liebschner et al., 2019). Metal ions were checked against the density and the potential coordinate ligands. Sites of methylation were identified by the presence of protruding density continuous from the rest of the chemical moiety and those of pseudouridylation by the presence of hydrogen bond acceptor (mostly water) near the N1 atom of pseudouridine. The presence of modifications is checked against the snoRNA (https://people.biochem.umass.edu/fournierlab/snornadb/mastertable.php)

database (Piekna-Przybylska et al., 2007) and the literature (Sloan et al., 2017). Modified nucleotides and protein residues were build using PYMOL (DeLano) while the restraint parameters were generated by JLIGAND (Lebedev et al., 2012) for PHENIX refinement and COOT (Emsley et al., 2010) display. The final models were iteratively refined with the real-space refinement module in PHENIX and manual checking/remodeling in COOT until the best map correlation coefficients and geometric values were reached (Table S2).

Structure Comparisons 
We compared any given pair of densities with UCSF Chimera (Pettersen et al., 2004) in following manner. The two 80 S densities segmented by the watershed segmentation feature available in UCSF Chimera (Pettersen et al., 2004) were both aligned against a reference 605 density. The bodies of the $40 S$ in both $80 S$ densities were compared by displaying the location and degree of rotation of the transformation (ratchet) with the command "measure rotation". Subsequently, the bodies of the $40 S$ in both $80 S$ densities were aligned against a reference body density. The segmented heads of the $40 S$ in the $80 S$ densities were compared by displaying the location and degree of rotation of the transformation (swivel) with the same command.

\section{Multi-body Analysis}

Multi-body refinement was carried out using Relion-3.1 (Nakane et al., 2018) by defining three bodies (60S, 40S body, and 40S head) with a rotation range of 10 degrees in the order of $40 \mathrm{~S}$ body to $60 \mathrm{~S}$ and then $40 \mathrm{~S}$ head to $40 \mathrm{~S}$ body. Top three represented eigenvectors were analyzed for a given structure and each is are shown as morphed movies (Supplementary Movies 1-6) as well as a set of transformation axes described above between the two extreme maps within each eigenvector (Supplementary Figure 6). 


\section{Figure Captions}

Figure 1. Growth and polysome profile comparison among the wild-type (top), nop1-D243A (middle), and cbf5-D95A (bottom) yeast cells. For growth analysis, cells were grown in a liquid YPD medium to saturation, washed twice and diluted with sterile water to OD of $1.0(600 \mathrm{~nm})$ before being spotted on solid YPD plate at each specified temperature. For polysome profile analysis, extracts from the cells grown to log phase were fractionated on a 10\%-50\% sucrose gradient and detected by UV absorbance at $254 \mathrm{~nm}$.

Figure 2. Overview of cryoEM structures of both the fully modified (nop1-D243A, green) and pseudouridine-free (cbf5-D95A, blue) yeast ribosome. "LSU” denotes the large subunit while "head" and "body" denote the head and body domains of the small subunit, respectively. The density belonging to the hibernating factor Stm1 is colored in red. Locations of pseudouridine and 2'-O-methylation are marked by purple and cyan, respectively.

Figure 3. Comparison of ribosome conformations. Each classified and Stm1-bound ribosome conformation was compared with the non-rotated conformation (Structure I of nop1-D243A ribosome) except for Structure I of nop1-D243A that was compared with the previously known non-rotated structure (PDB ID: 3J78). The relationship between the two compared heads is indicated by the location and degree of rotation of the rotation axis in black (swivel). The relationship between the two compared bodies is indicated by the location and degree of rotation of the rotation axis in gray (ratchet). To reveal relative transformation relationships 
among the conformations, all rotation axes were also merged onto a single ribosome model and shown in different colors. Positive rotation is defined as clockwise when viewed into each rotation axis. The percentage of particles comprising each class over the total number of particles and the final resolution are shown in the parenthesis under each conformational class. A. Conformational distribution and relationships of the fully modified ribosome (nop1-D243A) structures. If a conformation is similar to a known ribosome structure, its PDB ID is indicated and if not, N.A. (not applicable) is indicated. B. Conformational distribution and relationships of the pseudouridine-free ribosome ( $c b f 5-\mathrm{D} 95 \mathrm{~A})$ structures. If a conformation is similar to a known ribosome structure, its PDB ID is indicated and if not, N.A. (not applicable) is indicated.

Figure 4. Observed modifications in key regions important to ribosome motions. A. Pair-wise displacement of the 25S rRNA from the rotated (PDB ID: 3J77) to the non-rotated transformation (PDB ID: 3J78) superimposed with sites of 2'-Omethylation (green) and pseoduridylation (red). The modification-rich, especially pseudouridine-rich, clusters coincide with three functional regions, the A-site figure (ASF, dark green bar), the intersubunit bridge (ISB, blue bar), and the peptidyl transfer center (PTC, orange bar). B. Observed pseudouridine distributions in ASF, ISB, and PTC, of the nop1-D243A ribosome and in relation to the rpL10 (magenta) and rpL3 (pink) proteins. The rotation axis marks the major location of ratchet motion in fully modified ribosome. Insets illustrate the observed intra-strand interactions by pseudouridine within the three clusters. Dashed lines depict water-mediated contacts of the N1 atom of a pseudouridine to the phosphate sugar backbone of either self or adjacent nucleotides. Pseudouridine 
nucleotids not associated with dashed lines indicate weak or absence of density supporting the interactions. C. Examples of how pseudouridine in ASF $(\psi 2133)$ and PTC ( $\psi 2826$ and $\psi 2865, \psi 2880$, and $\psi 2944)$ participate in networks of hydrogen bonds observed in the nop1-D243A ribosome. Dash lines represent the residues 101-113 not modeled for rpL10p due to lack of density.

\section{Deposition of Electron Cryomicroscope Data}

The atomic coordinates and associated density maps have deposited at Protein Data Bank with accession codes 7MPJ \& EMD-23935 for the nop1-D243 ribosome and 7MPI \& EMD-23934 for the cbf5-D95A ribosome, respectively.

\section{Acknowledgments}

This work was supported by NIH grant R01 GM124622 to H.L. The authors also acknowledge the use of instruments at the Biological Science Imaging Resource supported by Florida State University. The Titan was funded from NIH grant S10 RR025080. The BioQuantum/K3 was funded from NIH grant U24 GM116788. The Vitrobot Mk IV was funded from NIH grant S10 RR024564. The Solaris Plasma Cleaner was funded from NIH grant S10 RR024564. The DE-64 was funded from from NIH grant U24 GM116788.

\section{Author Contributions}

Y.Z. and H.L. designed all experiments. Y.Z. constructed all yeast strains, performed polysome profiling, and purified ribosomes. Y.Z. and J.R. prepared cryoEM grids and collected data. J.R. performed cryoEM analysis with the 
assistance of Y.Z.. Y.Z., J.R. and H.L analyzed data, wrote and edited manuscript and made figures.

Conflict of interest

The authors declare that they have no conflict of interest.

\section{List of Supplementary materials}

Supplementary Table 1. List of Modifications for the nop1-D243A and cbf5-D95A Ribosome.

Supplementary Table 2. Data Acquisition, Processing and Model Refinement.

Supplementary Figure 1. Related to Figures 1, 2, 3, \& 4. Sanger sequencing verification of the $c b f 5-\mathrm{D} 95 \mathrm{~A}(\mathrm{~A})$ and nop1-D243A (B) mutations.

Supplementary Figure 2. Related to Figures 2, 3, \& 4. Cryo-EM image analysis flow chart of nop1-D243A ribosome.

Supplementary Figure 3. Related to Figures 2, 3, \& 4. Cryo-EM image analysis flow chart of $c b f 5-\mathrm{D} 95 \mathrm{~A}$.

Supplementary Figure 4. Related to Figures, 2, 3, \& 4. Electron potential density for selected nucloetides that are predicted to be pseudouridylated (A) or 2'-Omethylated (B). 
Supplementary Figure 5. Related to Figure 3. Comparison of known ribosome conformations.

Supplementary Figure 6. Related to Figure 3. 3D multivaribilty analysis for the nop1-D243A (green) and cbf5-D95A (blue) ribosome.

Supplementary Figure 7. Related to Figure 4. Mapping modification sites on the nucleotide pair-wise displacement plot for the small subunit ribosomal RNA (18S rRNA) when transforming the rotated (PDB ID: 3J77) to the non-rotated (PDB ID: 3J78) ribosome conformation.

Supplementary Figure 8. Related to Figure 4. The correspondng electron potential density maps in the $c b f 5$-D95A ribosome around the pseodouridine clusters on the large subunit shown in Figure 4C for nop1-D243A ribosome.

Supplementary Movie 1. Related to Figure 3 \& Supplementary Figure 6. Domain motions representing eigenvector 1 resulted from multivaribility analysis of nop1D243A ribosome.

Supplementary Movie 2. Related to Figure 3 \& Supplementary Figure 6. Domain motions representing eigenvector 1 resulted from multivaribility analysis of $C b f 5-$ D95A ribosome. 
Supplementary Movie 3. Related to Figure 3 \& Supplementary Figure 6. Domain motions representing eigenvector 2 resulted from multivaribility analysis of nop1D243A ribosome.

Supplementary Movie 4. Related to Figure 3 \& Supplementary Figure 6. Domain motions representing eigenvector 2 resulted from multivaribility analysis of $C b f 5-$ D95A ribosome.

Supplementary Movie 5. Related to Figure 3 \& Supplementary Figure 6. Domain motions representing eigenvector 3 resulted from multivaribility analysis of nop1D243A ribosome.

Supplementary Movie 6. Related to Figure 3 \& Supplementary Figure 6. Domain motions representing eigenvector 3 resulted from multivaribility analysis of $C b f 5$ D95A ribosome.

\section{References}

Abeyrathne, P.D., Koh, C.S., Grant, T., Grigorieff, N., and Korostelev, A.A. (2016).

Ensemble cryo-EM uncovers inchworm-like translocation of a viral IRES through the ribosome. eLife 5.

Aittaleb, M., Visone, T., Fenley, M.O., and Li, H. (2004). Structural and thermodynamic evidence for a stabilizing role of Nop5p in S-adenosyl-L-methionine binding to fibrillarin. The Journal of biological chemistry 279, 41822-41829. Ashe, M.P., De Long, S.K., and Sachs, A.B. (2000). Glucose depletion rapidly inhibits translation initiation in yeast. Molecular biology of the cell 11,833-848. Babaian, A., Rothe, K., Girodat, D., Minia, I., Djondovic, S., Milek, M., Spencer Miko, S.E., Wieden, H.J., Landthaler, M., Morin, G.B., et al. (2020). Loss of m(1)acp(3)Psi Ribosomal RNA Modification Is a Major Feature of Cancer. Cell reports 31, 107611. Baxter-Roshek, J.L., Petrov, A.N., and Dinman, J.D. (2007). Optimization of ribosome structure and function by rRNA base modification. PloS one 2, e174. 
Bellodi, C., Kopmar, N., and Ruggero, D. (2010). Deregulation of oncogene-induced senescence and p53 translational control in X-linked dyskeratosis congenita. The EMBO journal 29, 1865-1876.

Ben-Shem, A., Garreau de Loubresse, N., Melnikov, S., Jenner, L., Yusupova, G., and Yusupov, M. (2011). The structure of the eukaryotic ribosome at 3.0 A resolution. Science 334, 1524-1529.

Ben-Shem, A., Jenner, L., Yusupova, G., and Yusupov, M. (2010). Crystal structure of the eukaryotic ribosome. Science 330, 1203-1209.

Cornish, P.V., Ermolenko, D.N., Noller, H.F., and Ha, T. (2008). Spontaneous intersubunit rotation in single ribosomes. Mol Cell 30, 578-588.

Decatur, W.A., and Fournier, M.J. (2003). RNA-guided nucleotide modification of ribosomal and other RNAs. The Journal of biological chemistry 278, 695-698.

DeLano, W.L. The PyMOL Molecular Graphics System. DeLano Scientific LLC, San Carlos, CA USA http://www.pymol.org.

Dragon, F., Gallagher, J.E., Compagnone-Post, P.A., Mitchell, B.M., Porwancher, K.A., Wehner, K.A., Wormsley, S., Settlage, R.E., Shabanowitz, J., Osheim, Y., et al. (2002). A large nucleolar U3 ribonucleoprotein required for 18S ribosomal RNA biogenesis. Nature 417, 967-970.

Emsley, P., Lohkamp, B., Scott, W.G., and Cowtan, K. (2010). Features and development of Coot. Acta crystallographica Section D, Biological crystallography 66, 486-501.

Fatica, A., and Tollervey, D. (2002). Making ribosomes. Curr Opin Cell Biol 14, 313318.

Feder, M., Pas, J., Wyrwicz, L.S., and Bujnicki, J.M. (2003). Molecular phylogenetics of the RrmJ/fibrillarin superfamily of ribose 2'-0-methyltransferases. Gene 302, 129138.

Frank, J. (2016). Whither Ribosome Structure and Dynamics Research? (A

Perspective). Journal of molecular biology 428, 3565-3569.

Frank, J., and Gonzalez, R.L., Jr. (2010). Structure and dynamics of a processive

Brownian motor: the translating ribosome. Annual review of biochemistry 79, 381-

412.

Gardner, J.M., and Jaspersen, S.L. (2014). Manipulating the yeast genome: deletion, mutation, and tagging by PCR. Methods Mol Biol 1205, 45-78.

Ghalei, H., Trepreau, J., Collins, J.C., Bhaskaran, H., Strunk, B.S., and Karbstein, K. (2017). The ATPase Fap7 Tests the Ability to Carry Out Translocation-like Conformational Changes and Releases Dim1 during 40S Ribosome Maturation. Mol Cell 67, 990-1000 e1003.

Gigova, A., Duggimpudi, S., Pollex, T., Schaefer, M., and Kos, M. (2014). A cluster of methylations in the domain IV of $25 \mathrm{~S}$ rRNA is required for ribosome stability. RNA 20, 1632-1644.

Hager, J., Staker, B.L., Bugl, H., and Jakob, U. (2002). Active site in RrmJ, a heat shockinduced methyltransferase. The Journal of biological chemistry 277, 41978-41986. Heiss, N.S., Knight, S.W., Vulliamy, T.J., Klauck, S.M., Wiemann, S., Mason, P.J., Poustka, A., and Dokal, I. (1998). X-linked dyskeratosis congenita is caused by mutations in a highly conserved gene with putative nucleolar functions. Nat Genet 19, 32-38. 
Hodel, A.E., Gershon, P.D., Shi, X., and Quiocho, F.A. (1996). The 1.85 A structure of vaccinia protein VP39: a bifunctional enzyme that participates in the modification of both mRNA ends. Cell 85, 247-256. Jack, K., Bellodi, C., Landry, D.M., Niederer, R.O., Meskauskas, A., Musalgaonkar, S., Kopmar, N., Krasnykh, O., Dean, A.M., Thompson, S.R., et al. (2011). rRNA pseudouridylation defects affect ribosomal ligand binding and translational fidelity from yeast to human cells. Mol Cell 44, 660-666.

Jiang, J., Seo, H., and Chow, C.S. (2016). Post-transcriptional Modifications Modulate rRNA Structure and Ligand Interactions. Acc Chem Res 49, 893-901.

King, T.H., Liu, B., McCully, R.R., and Fournier, M.J. (2003). Ribosome structure and activity are altered in cells lacking snoRNPs that form pseudouridines in the peptidyl transferase center. Mol Cell 11, 425-435.

Korostelev, A., Ermolenko, D.N., and Noller, H.F. (2008). Structural dynamics of the ribosome. Curr Opin Chem Biol 12, 674-683.

Kucukelbir, A., Sigworth, F.J., and Tagare, H.D. (2014). Quantifying the local resolution of cryo-EM density maps. Nature methods 11, 63-65.

Lebedev, A.A., Young, P., Isupov, M.N., Moroz, O.V., Vagin, A.A., and Murshudov, G.N. (2012). JLigand: a graphical tool for the CCP4 template-restraint library. Acta crystallographica Section D, Biological crystallography 68, 431-440.

Leppik, M., Liiv, A., and Remme, J. (2017). Random pseuoduridylation in vivo reveals critical region of Escherichia coli 23S rRNA for ribosome assembly. Nucleic Acids

Res 45, 6098-6108.

Liang, B., and Li, H. (2011). Structures of ribonucleoprotein particle modification enzymes. Quarterly reviews of biophysics 44, 95-122.

Liang, B., Zhou, J., Kahen, E., Terns, R.M., Terns, M.P., and Li, H. (2009a). Structure of a functional ribonucleoprotein pseudouridine synthase bound to a substrate RNA. Nature structural \& molecular biology 16, 740-746.

Liang, X.H., Liu, Q., and Fournier, M.J. (2007). rRNA modifications in an intersubunit bridge of the ribosome strongly affect both ribosome biogenesis and activity. Mol Cell 28, 965-977.

Liang, X.H., Liu, Q., and Fournier, M.J. (2009b). Loss of rRNA modifications in the decoding center of the ribosome impairs translation and strongly delays pre-rRNA processing. RNA 15, 1716-1728.

Liebschner, D., Afonine, P.V., Baker, M.L., Bunkoczi, G., Chen, V.B., Croll, T.I., Hintze, B., Hung, L.W., Jain, S., McCoy, A.J., et al. (2019). Macromolecular structure determination using X-rays, neutrons and electrons: recent developments in Phenix. Acta Crystallogr D 75, 861-877.

Ling, C., and Ermolenko, D.N. (2016). Structural insights into ribosome translocation. Wiley interdisciplinary reviews RNA 7, 620-636.

Liu, B., Liang, X.H., Piekna-Przybylska, D., Liu, Q., and Fournier, M.J. (2008). Mistargeted methylation in rRNA can severely impair ribosome synthesis and activity. RNA biology 5, 249-254.

Maxwell, E.S., and Fournier, M.J. (1995). The small nucleolar RNAs. Annual review of biochemistry 64, 897-934. 
Meskauskas, A., and Dinman, J.D. (2008). Ribosomal protein L3 functions as a 'rocker switch' to aid in coordinating of large subunit-associated functions in eukaryotes and Archaea. Nucleic Acids Res 36, 6175-6186.

Mitchell, J.R., Cheng, J., and Collins, K. (1999). A box H/ACA small nucleolar RNA-like domain at the human telomerase RNA 3' end. Molecular and cellular biology 19, 567-576.

Moore, P.B. (2012). How should we think about the ribosome? Annu Rev Biophys 41, 1-19.

Nakane, T., Kimanius, D., Lindahl, E., and Scheres, S.H.W. (2018). Characterisation of molecular motions in cryo-EM single-particle data by multi-body refinement in RELION. eLife 7.

Natchiar, S.K., Myasnikov, A.G., Kratzat, H., Hazemann, I., and Klaholz, B.P. (2017).

Visualization of chemical modifications in the human $80 \mathrm{~S}$ ribosome structure.

Nature 551, 472-477.

Noon, K.R., Bruenger, E., and McCloskey, J.A. (1998). Posttranscriptional

modifications in $16 \mathrm{~S}$ and 23S rRNAs of the archaeal hyperthermophile Sulfolobus

solfataricus. Journal of bacteriology 180, 2883-2888.

Pettersen, E.F., Goddard, T.D., Huang, C.C., Couch, G.S., Greenblatt, D.M., Meng, E.C., and Ferrin, T.E. (2004). UCSF Chimera--a visualization system for exploratory research and analysis. J Comput Chem 25, 1605-1612.

Piekna-Przybylska, D., Decatur, W.A., and Fournier, M.J. (2007). New bioinformatic tools for analysis of nucleotide modifications in eukaryotic rRNA. RNA 13, 305-312. Piekna-Przybylska, D., Przybylski, P., Baudin-Baillieu, A., Rousset, J.P., and Fournier, M.J. (2008). Ribosome performance is enhanced by a rich cluster of pseudouridines in the A-site finger region of the large subunit. The Journal of biological chemistry 283, 26026-26036.

Polikanov, Y.S., Melnikov, S.V., Soll, D., and Steitz, T.A. (2015). Structural insights into the role of rRNA modifications in protein synthesis and ribosome assembly. Nature structural \& molecular biology 22, 342-344.

Punjani, A., Rubinstein, J.L., Fleet, D.J., and Brubaker, M.A. (2017). cryoSPARC: algorithms for rapid unsupervised cryo-EM structure determination. Nature methods 14, 290-296.

Rai, J., Parker, M.D., Huang, H., Choy, S., Ghalei, H., Johnson, M.C., Karbstein, K., and Stroupe, M.E. (2021). An open interface in the pre-80S ribosome coordinated by ribosome assembly factors Tsr1 and Dim1 enables temporal regulation of Fap7. RNA 27, 221-233.

Rakauskaite, R., Liao, P.Y., Rhodin, M.H., Lee, K., and Dinman, J.D. (2011). A rapid, inexpensive yeast-based dual-fluorescence assay of programmed--1 ribosomal frameshifting for high-throughput screening. Nucleic Acids Res 39, e97.

Scaiola, A., Pena, C., Weisser, M., Bohringer, D., Leibundgut, M., Klingauf-Nerurkar, P., Gerhardy, S., Panse, V.G., and Ban, N. (2018). Structure of a eukaryotic cytoplasmic pre-40S ribosomal subunit. The EMBO journal 37.

Schmeing, T.M., and Ramakrishnan, V. (2009). What recent ribosome structures have revealed about the mechanism of translation. Nature 461, 1234-1242.

Sengupta, A., Rice, G.M., and Weeks, K.M. (2019). Single-molecule correlated chemical probing reveals large-scale structural communication in the ribosome and 
the mechanism of the antibiotic spectinomycin in living cells. PLoS biology 17, e3000393.

Sharma, S., and Lafontaine, D.L.J. (2015). 'View From A Bridge': A New Perspective on Eukaryotic rRNA Base Modification. Trends in biochemical sciences 40, 560-575. Simsek, D., Tiu, G.C., Flynn, R.A., Byeon, G.W., Leppek, K., Xu, A.F., Chang, H.Y., and Barna, M. (2017). The Mammalian Ribo-interactome Reveals Ribosome Functional Diversity and Heterogeneity. Cell 169, 1051-1065 e1018.

Sloan, K.E., Warda, A.S., Sharma, S., Entian, K.D., Lafontaine, D.L.J., and Bohnsack, M.T. (2017). Tuning the ribosome: The influence of rRNA modification on eukaryotic ribosome biogenesis and function. RNA biology 14, 1138-1152.

Spedaliere, C.J., Ginter, J.M., Johnston, M.V., and Mueller, E.G. (2004). The pseudouridine synthases: revisiting a mechanism that seemed settled. J Am Chem Soc 126, 12758-12759.

Sulima, S.O., Gulay, S.P., Anjos, M., Patchett, S., Meskauskas, A., Johnson, A.W., and Dinman, J.D. (2014). Eukaryotic rpL10 drives ribosomal rotation. Nucleic Acids Res 42, 2049-2063.

Suloway, C., Pulokas, J., Fellmann, D., Cheng, A., Guerra, F., Quispe, J., Stagg, S., Potter, C.S., and Carragher, B. (2005). Automated molecular microscopy: the new Leginon system. J Struct Biol 151, 41-60.

Svidritskiy, E., Brilot, A.F., Koh, C.S., Grigorieff, N., and Korostelev, A.A. (2014). Structures of yeast $80 \mathrm{~S}$ ribosome-tRNA complexes in the rotated and nonrotated conformations. Structure 22, 1210-1218.

Tiku, V., Kew, C., Mehrotra, P., Ganesan, R., Robinson, N., and Antebi, A. (2018). Nucleolar fibrillarin is an evolutionarily conserved regulator of bacterial pathogen resistance. Nature communications 9, 3607.

Waldron, C., Jund, R., and Lacroute, F. (1977). Evidence for a high proportion of inactive ribosomes in slow-growing yeast cells. The Biochemical journal 168, 409415.

Watkins, N.J., and Bohnsack, M.T. (2012). The box C/D and H/ACA snoRNPs: key players in the modification, processing and the dynamic folding of ribosomal RNA. Wiley interdisciplinary reviews RNA 3, 397-414.

Yoon, A., Peng, G., Brandenburger, Y., Zollo, O., Xu, W., Rego, E., and Ruggero, D. (2006). Impaired control of IRES-mediated translation in X-linked dyskeratosis congenita. Science 312, 902-906.

Yu, Y.T., and Meier, U.T. (2014). RNA-guided isomerization of uridine to pseudouridine--pseudouridylation. RNA biology 11, 1483-1494.

Zebarjadian, Y., King, T., Fournier, M.J., Clarke, L., and Carbon, J. (1999). Point mutations in yeast CBF5 can abolish in vivo pseudouridylation of rRNA. Molecular and cellular biology 19, 7461-7472.

Zhang, K. (2016). Gctf: Real-time CTF determination and correction. J Struct Biol 193, 1-12.

Zheng, S.Q., Palovcak, E., Armache, J.P., Verba, K.A., Cheng, Y., and Agard, D.A. (2017). MotionCor2: anisotropic correction of beam-induced motion for improved cryoelectron microscopy. Nature methods 14, 331-332. 
bioRxiv preprint doi: https://doi.org/10.1101/2021.06.02.446812; this version posted June 2, 2021. The copyright holder for this preprint (which was not certified by peer review) is the author/funder, who has granted bioRxiv a license to display the preprint in perpetuity. It is made available under aCC-BY-ND 4.0 International license.

Zivanov, J., Nakane, T., Forsberg, B.O., Kimanius, D., Hagen, W.J., Lindahl, E., and Scheres, S.H. (2018). New tools for automated high-resolution cryo-EM structure determination in RELION-3. eLife 7. 


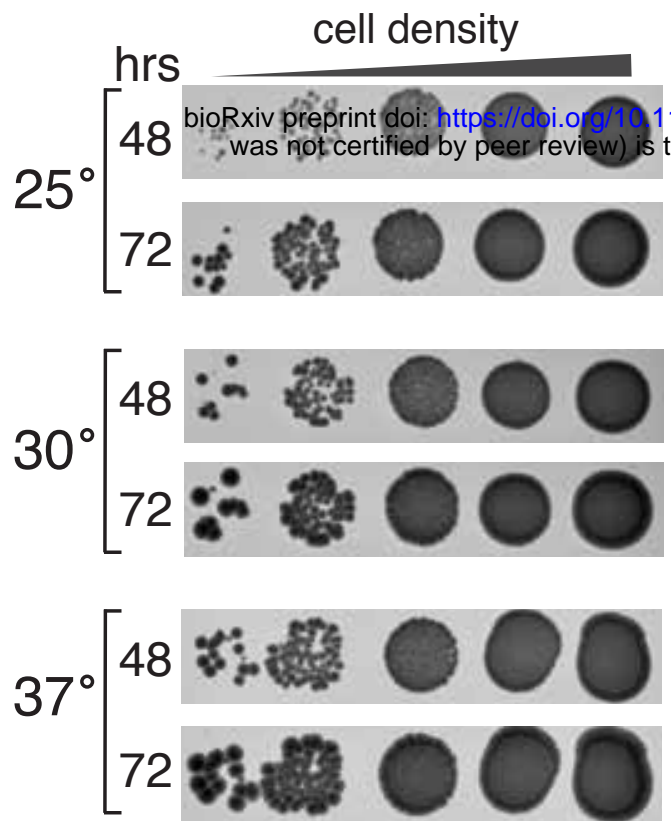

\section{5}

101/2021.06.02.446812; this version posted June 2, 2021. The \&OSght holder for this preprint (which the author/funder, who has granted bioRxiv a license to display th preprint in perpetuity. It is made

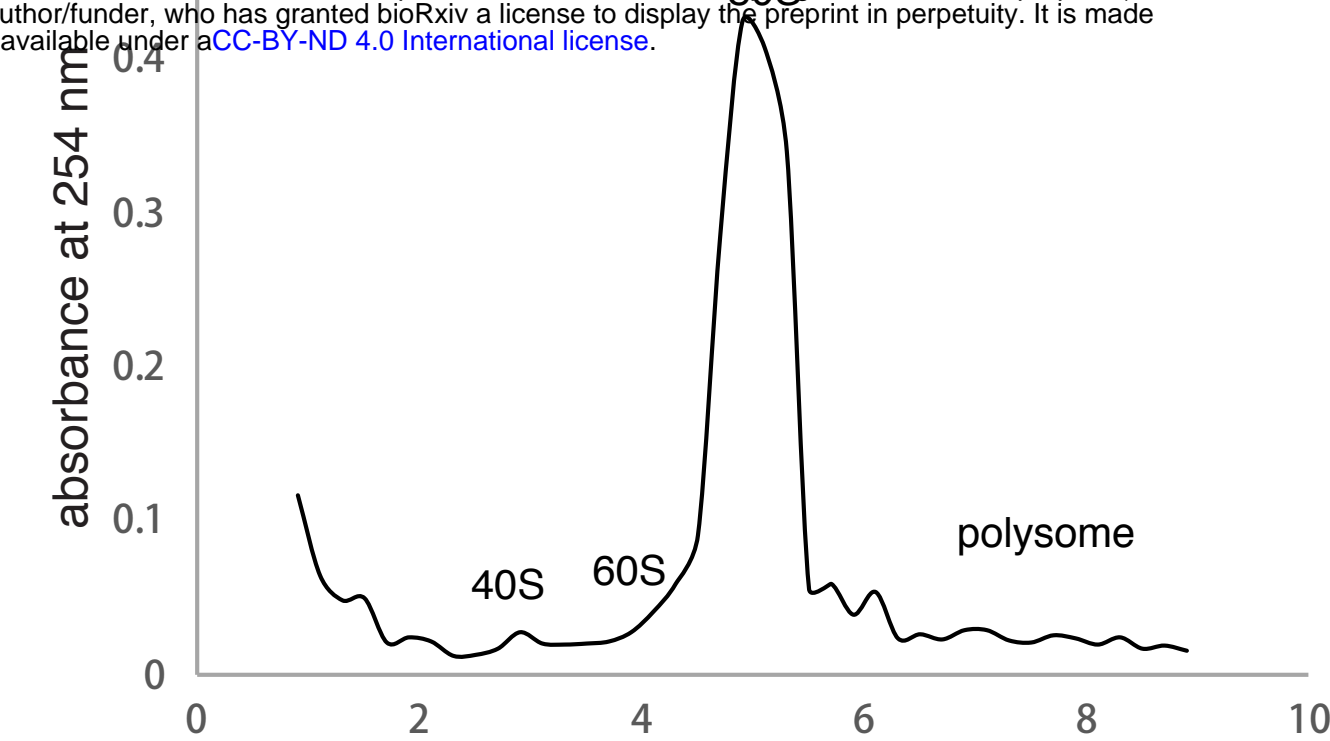

nop1-D243A

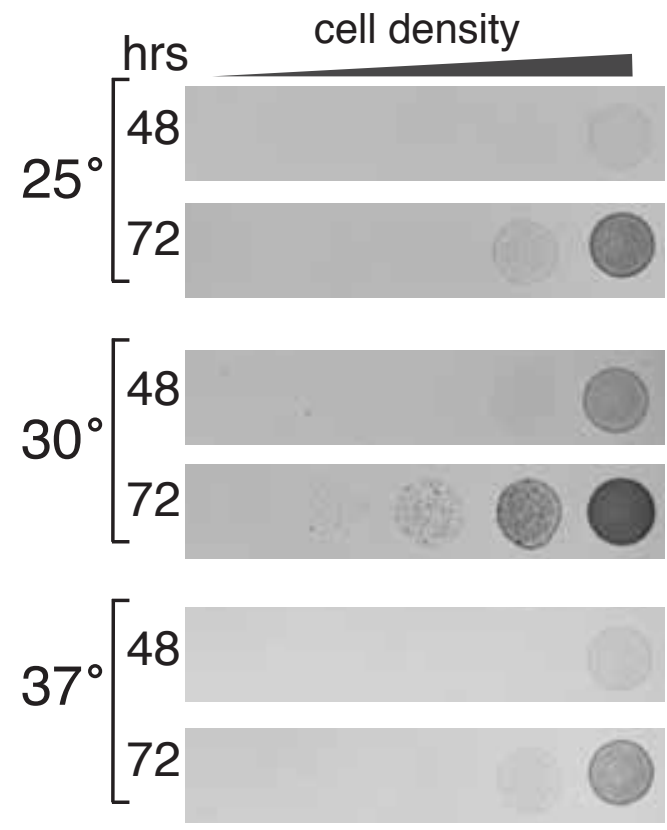

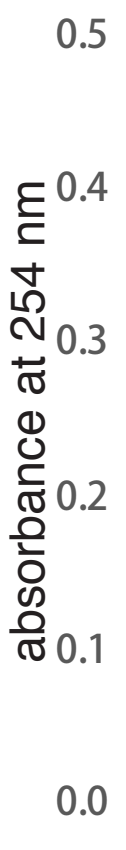

cbf5-D95A

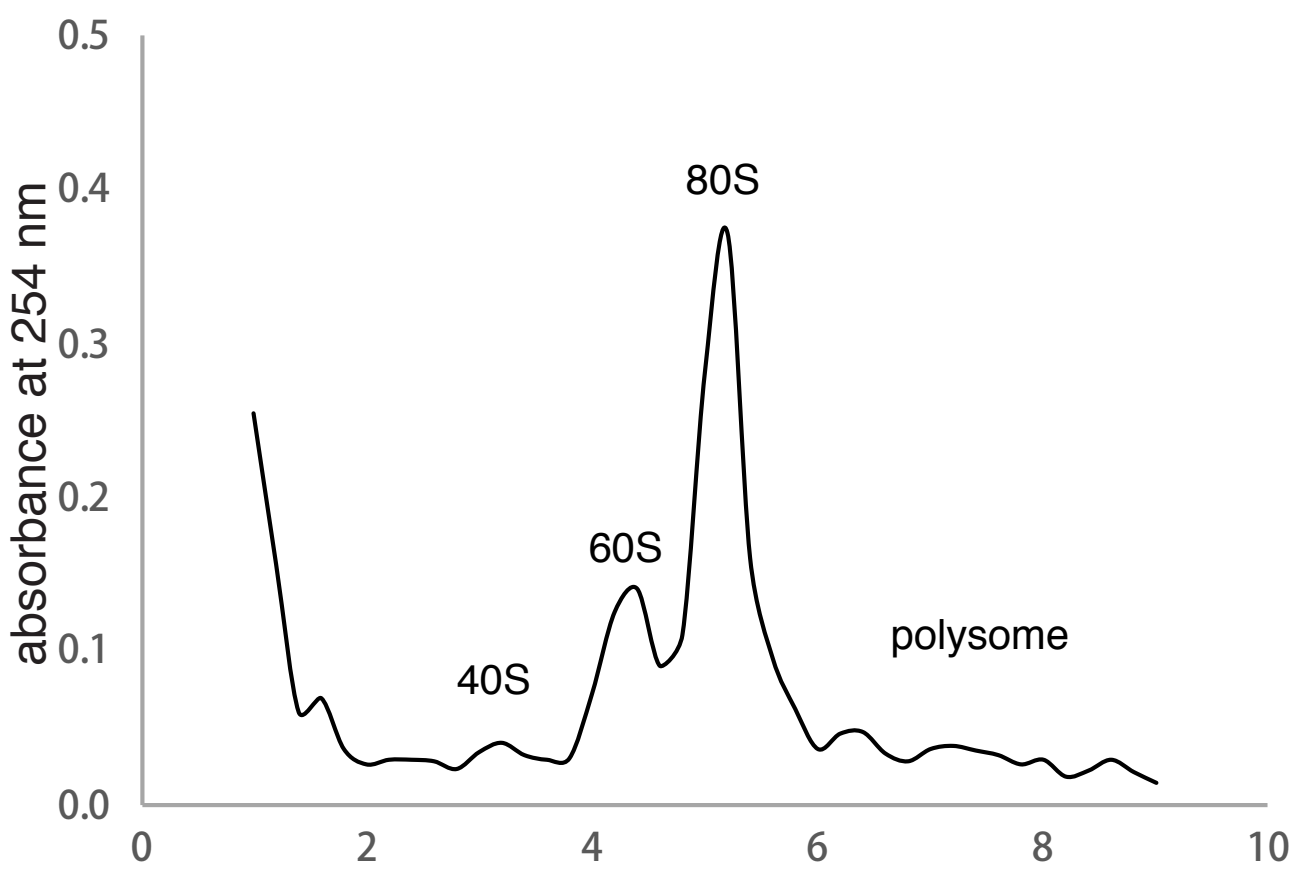


nop1-D243A ribosome
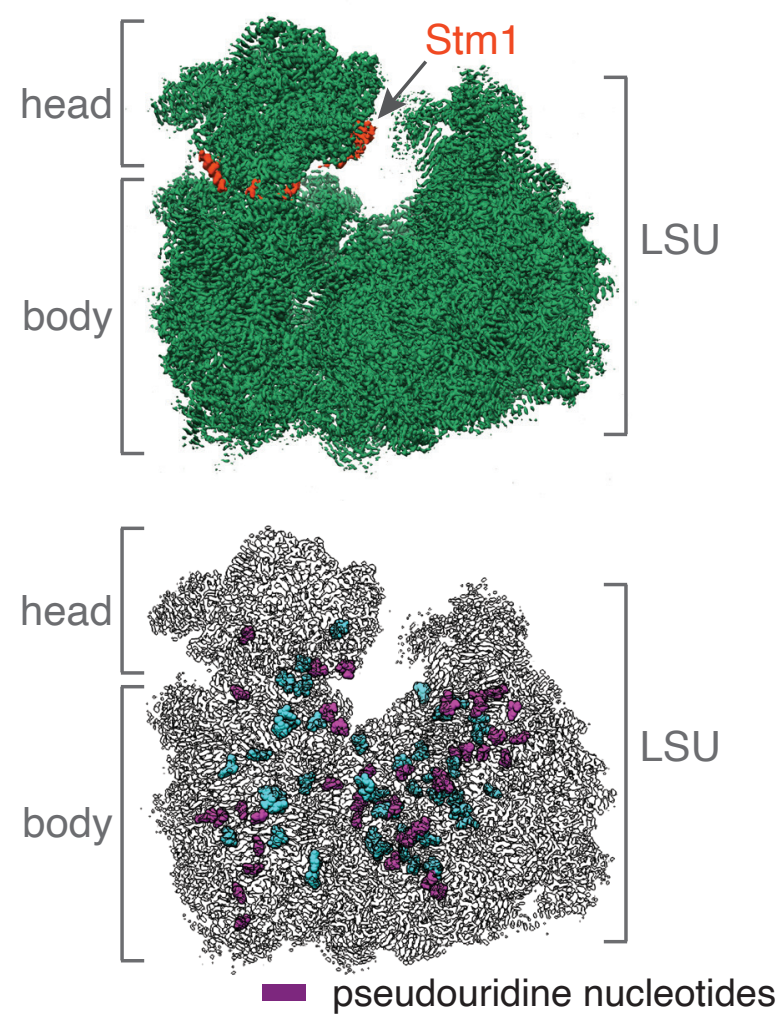

cbf5-D95A ribosome
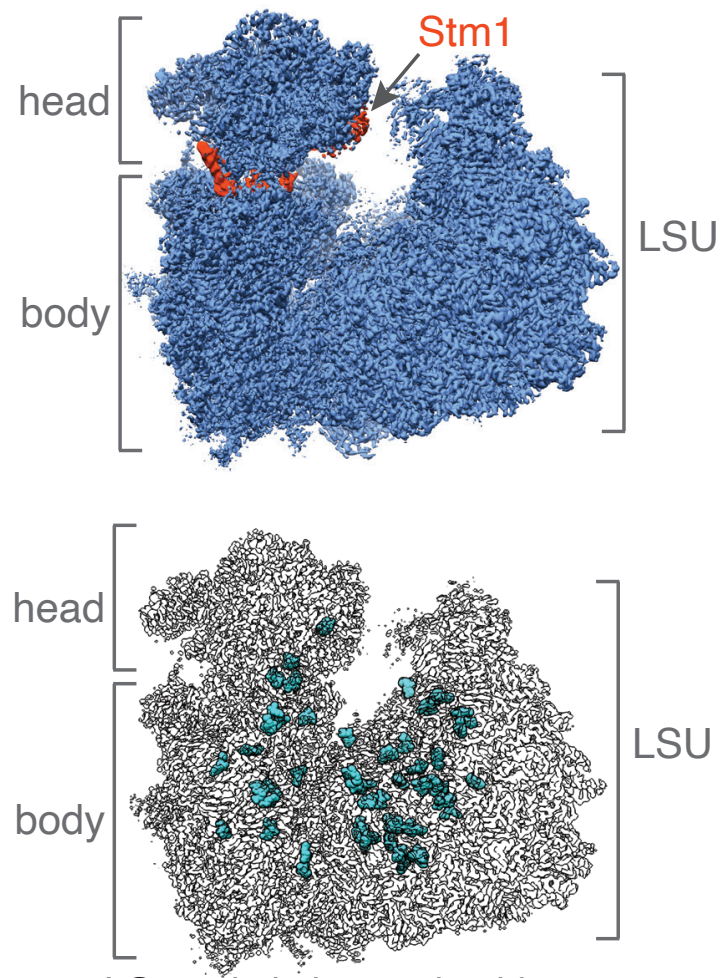

2'-O-methylation nucleotides 
A .pseudouridine

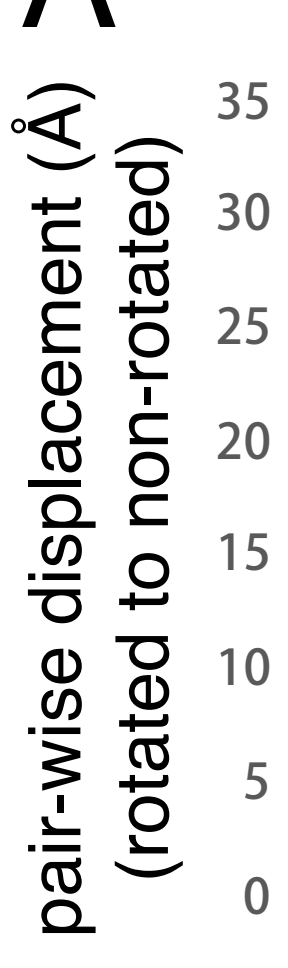

- 2'-O-methyl

ASF

Intersubuint
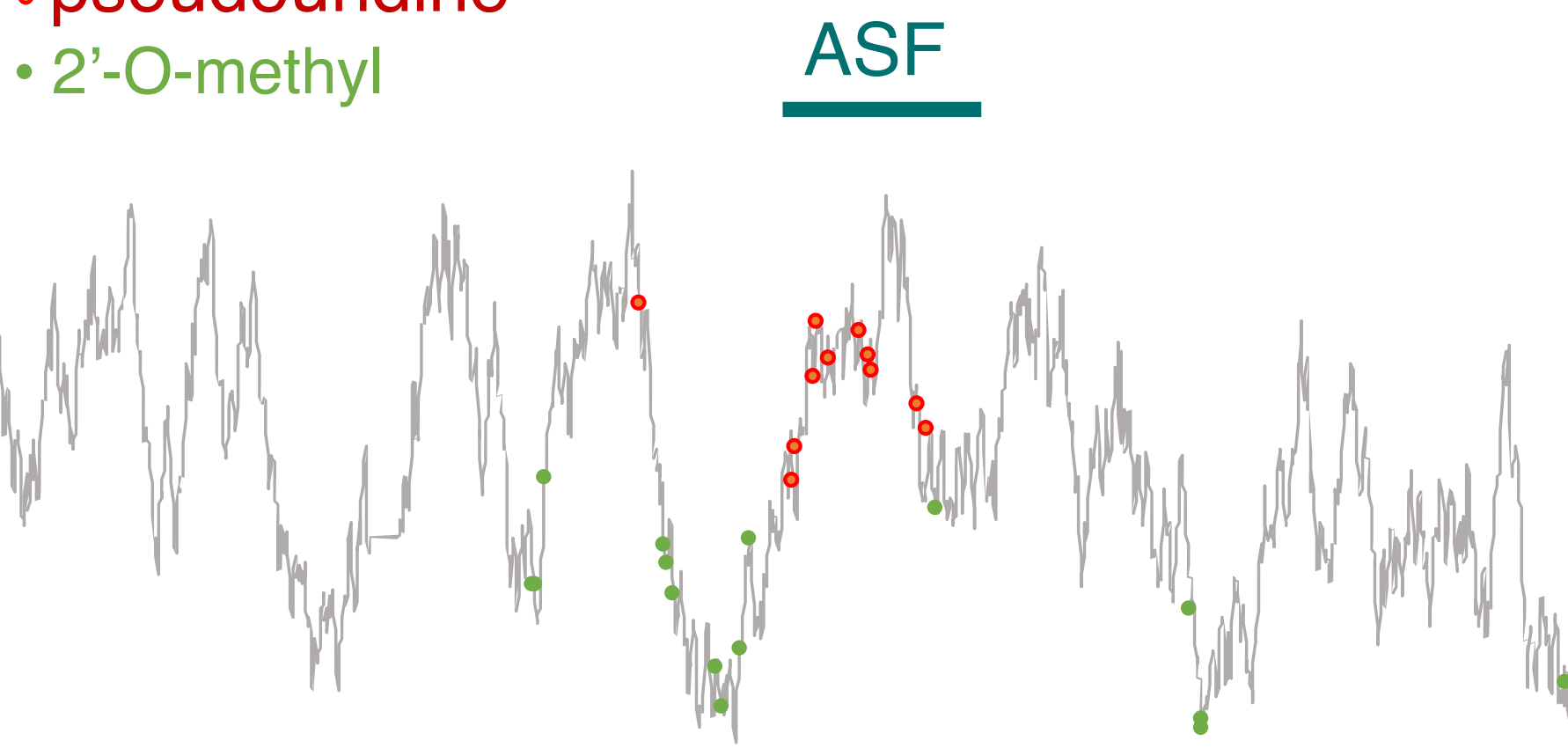

bridge

PTC

$0 \quad 200$

$600 \quad 800$

$\begin{array}{lllll}1000 & 1200 & 1400 & 1600 & 1800\end{array}$

$2000 \quad 2200 \quad 2400$

\section{S nucleotide number}

B

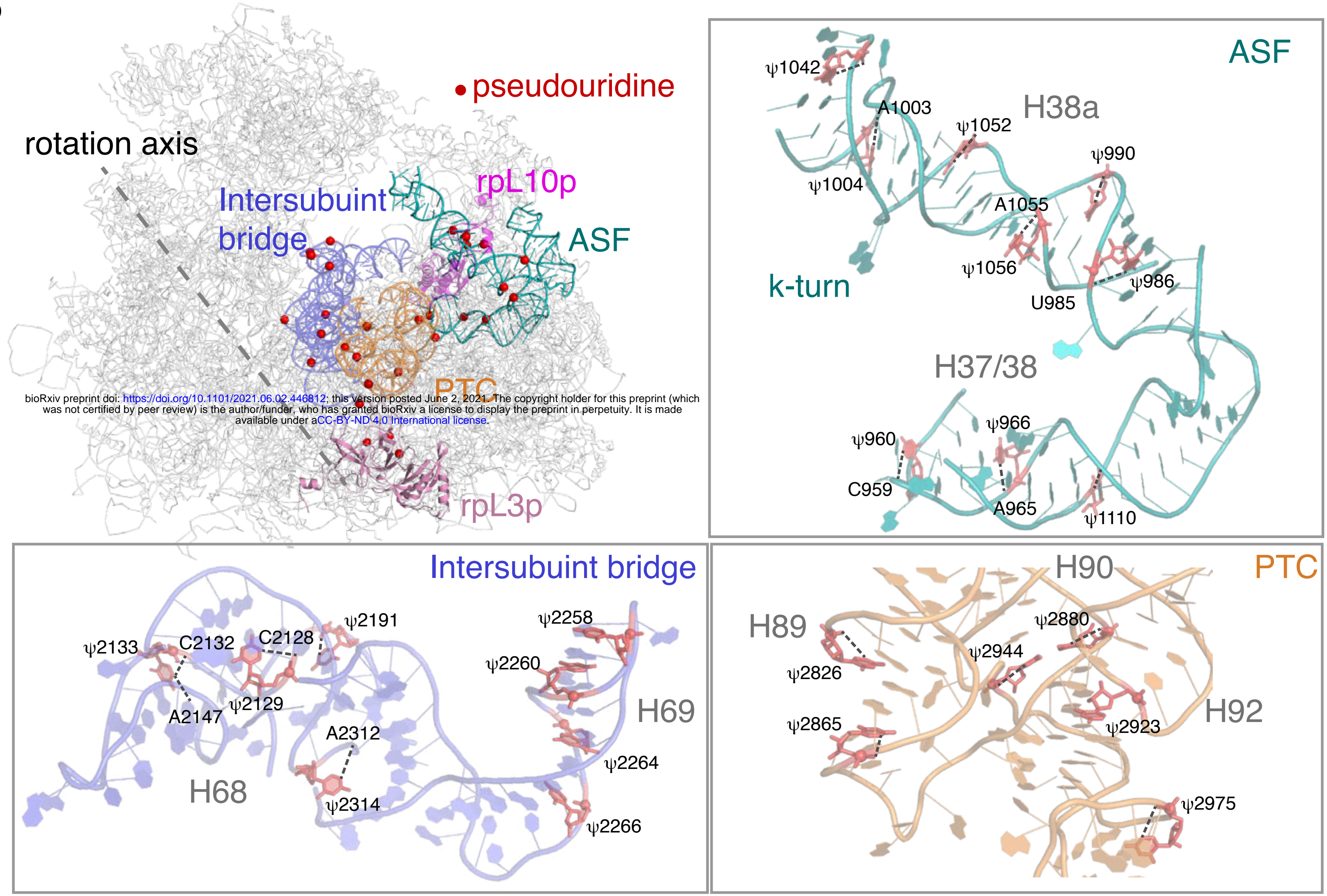

C
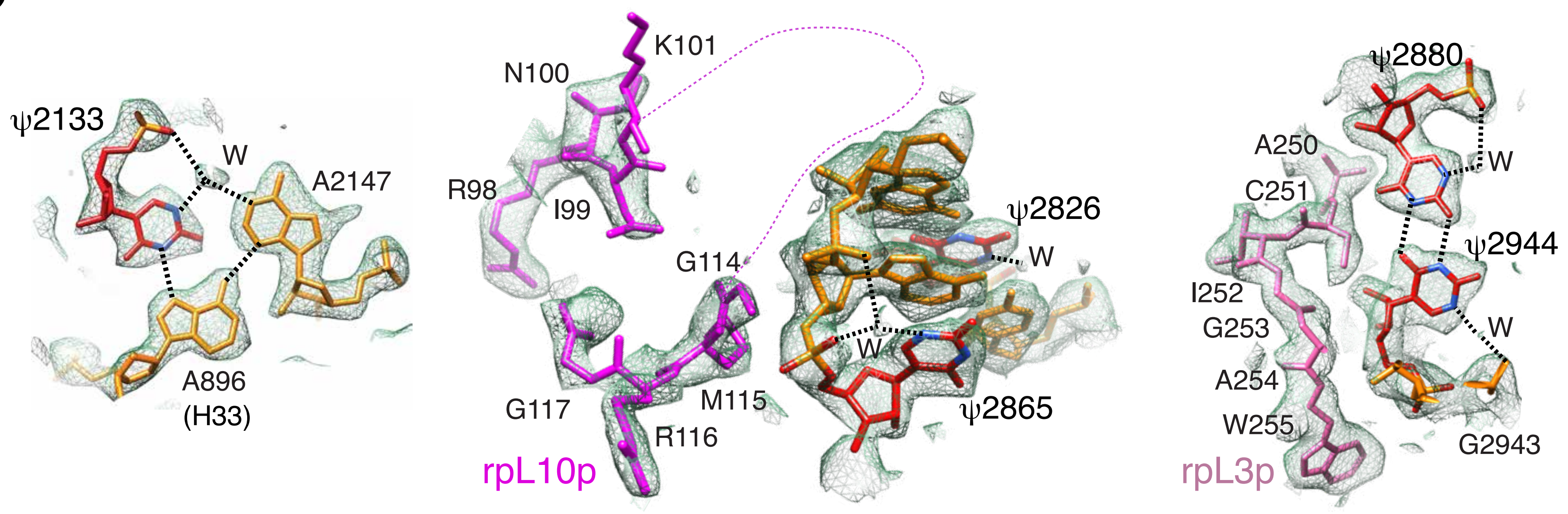


\title{
Supplementary Materials for
}

\section{Pseudouridine-free Ribosome Exhibits Distinct Inter-subunit Movements}

\author{
$\mathrm{Yu} \mathrm{Zhao}^{1}$, Jay Rai ${ }^{1}$, Hongguo $\mathrm{Yu}^{2}$ and Hong $\mathrm{Li}^{1,3 *}$
}

${ }^{1}$ Institute of Molecular Biophysics, ${ }^{2}$ Biological Science Department, ${ }^{3}$ Department of

Chemistry and Biochemistry, Florida State University, Tallahassee, FL 32306, USA.

${ }^{*}$ Corresponding author: hong.li@fsu.edu 
bioRxiv preprint doi: https://doi.org/10.1101/2021.06.02.446812; this version posted June 2, 2021. The copyright holder for this preprint (which was not certified by peer review) is the author/funder, who has granted bioRxiv a license to display the preprint in perpetuity. It is made available under aCC-BY-ND 4.0 International license.

Supplementary Table 1. List of Modifications for the nop1-D243A and cbf5-D95A Ribosome

$18 \mathrm{~S}$ modifications (\# built/\# total: $\psi=13 / 13 ; \mathrm{N}_{\mathrm{m}}=18 / 18$; base modified $=6 / 6$ )

\begin{tabular}{|c|c|c|c|c|c|}
\hline Nucleotide & Modification & Enzyme/snoRNP & $\begin{array}{l}\text { Partial } \\
\text { (ref.1) }\end{array}$ & $\begin{array}{l}\text { nop1- } \\
\text { D243A }\end{array}$ & $\begin{array}{l}c b f 5- \\
\text { D95A }\end{array}$ \\
\hline A28 & $\mathrm{N}_{\mathrm{m}}$ & snR74 & $\mathrm{N}$ & $\mathrm{Y}$ & $\mathrm{Y}$ \\
\hline A100 & $\mathrm{N}_{\mathrm{m}}$ & snR51 & $\mathrm{Y}$ & $\mathrm{Y}$ & Y \\
\hline U106 & $\Psi$ & snR44 & $\mathrm{N}$ & $\mathrm{Y}$ & $\mathrm{N}$ \\
\hline U120 & $\Psi$ & snR49 & $\mathrm{N}$ & $\mathrm{Y}$ & $\mathrm{N}$ \\
\hline U211 & $\Psi$ & snR49 & $\mathrm{Y}$ & $\mathrm{Y}$ & $\mathrm{N}$ \\
\hline U302 & $\Psi$ & snR49 & $\mathrm{N}$ & $\mathrm{Y}$ & $\mathrm{N}$ \\
\hline $\mathrm{C} 414$ & $\mathrm{~N}_{\mathrm{m}}$ & U14 & $\mathrm{N}$ & $\mathrm{Y}$ & $\mathrm{Y}$ \\
\hline A420 & $\mathrm{N}_{\mathrm{m}}$ & snR52 & $\mathrm{N}$ & $\mathrm{Y}$ & $\mathrm{Y}$ \\
\hline A436 & $\mathrm{N}_{\mathrm{m}}$ & snR87 & $\mathrm{Y}$ & $\mathrm{Y}$ & $\mathrm{Y}$ \\
\hline U466 & $\Psi$ & snR189 & $\mathrm{Y}$ & $\mathrm{Y}$ & $\mathrm{N}$ \\
\hline A541 & $\mathrm{N}_{\mathrm{m}}$ & snR41 & $\mathrm{N}$ & $\mathrm{Y}$ & $\mathrm{Y}$ \\
\hline G562 & $\mathrm{N}_{\mathrm{m}}$ & snR40 & $\mathrm{Y}$ & $\mathrm{Y}$ & $\mathrm{Y}$ \\
\hline U578 & $\mathrm{N}_{\mathrm{m}}$ & snR77 & $\mathrm{N}$ & $\mathrm{Y}$ & $\mathrm{Y}$ \\
\hline A619 & $\mathrm{N}_{\mathrm{m}}$ & snR47 & $\mathrm{N}$ & $\mathrm{Y}$ & $\mathrm{Y}$ \\
\hline U632 & $\Psi$ & snR161 & $\mathrm{Y}$ & $\mathrm{Y}$ & $\mathrm{N}$ \\
\hline U759 & $\Psi$ & snR80 & $\mathrm{N}$ & $\mathrm{Y}$ & $\mathrm{N}$ \\
\hline U766 & $\Psi$ & snR161 & $\mathrm{N}$ & $\mathrm{Y}$ & $\mathrm{N}$ \\
\hline A796 & $\mathrm{N}_{\mathrm{m}}$ & snR53 & $\mathrm{N}$ & $\mathrm{Y}$ & $\mathrm{Y}$ \\
\hline A974 & $\mathrm{N}_{\mathrm{m}}$ & snR54 & $\mathrm{N}$ & $\mathrm{Y}$ & $\mathrm{Y}$ \\
\hline U999 & $\Psi$ & snR31 & $\mathrm{Y}$ & $\mathrm{Y}$ & $\mathrm{N}$ \\
\hline C1007 & $\mathrm{N}_{\mathrm{m}}$ & snR79 & $\mathrm{N}$ & $\mathrm{Y}$ & $\mathrm{Y}$ \\
\hline G1126 & $\mathrm{N}_{\mathrm{m}}{ }^{\prime}$ & snR41 & $\mathrm{N}$ & $\mathrm{Y}$ & $\mathrm{Y}$ \\
\hline U1181 & $\Psi$ & snR85 & $\mathrm{N}$ & $\mathrm{Y}$ & $\mathrm{N}$ \\
\hline U1187 & $\Psi$ & snR36 & $\mathrm{N}$ & $\mathrm{Y}$ & $\mathrm{N}$ \\
\hline U1191 & $\mathrm{m}^{1} \mathrm{acp}^{3} \Psi$ & snR35/Emg1/Tsr3 & $\mathrm{N}$ & $\mathrm{Y}$ & $\mathrm{Y}^{\#}$ \\
\hline U1269 & $\mathrm{N}_{\mathrm{m}}$ & snR55 & $\mathrm{N}$ & $\mathrm{Y}$ & $\mathrm{Y}$ \\
\hline G1271 & $\mathrm{N}_{\mathrm{m}}$ & snR40 & $\mathrm{N}$ & $\mathrm{Y}$ & $\mathrm{Y}$ \\
\hline C1280 & $\mathrm{ac}^{4} \mathrm{C}$ & Kre33 & $\mathrm{Y}$ & $\mathrm{Y}$ & $\mathrm{Y}$ \\
\hline U1290 & $\Psi$ & snR83 & $\mathrm{N}$ & $\mathrm{Y}$ & $\mathrm{N}$ \\
\hline U1415 & $\Psi$ & snR83 & $\mathrm{Y}$ & $\mathrm{Y}$ & $\mathrm{N}$ \\
\hline G1428 & $\mathrm{N}_{\mathrm{m}}$ & snR56 & $\mathrm{N}$ & $\mathrm{Y}$ & $\mathrm{Y}$ \\
\hline G1572 & $\mathrm{N}_{\mathrm{m}}$ & snR57 & $\mathrm{N}$ & $\mathrm{Y}$ & $\mathrm{Y}$ \\
\hline G1575 & $\mathrm{m}^{7} \mathrm{G}$ & Bud23 & $\mathrm{N}$ & $Y$ & $\mathrm{~N}$ \\
\hline C1639 & $\mathrm{N}_{\mathrm{m}}$ & snR70 & $\mathrm{Y}$ & $\mathrm{Y}$ & $\mathrm{Y}$ \\
\hline A1773 & $\mathrm{ac}^{4} \mathrm{C}$ & Kre33 & $\mathrm{N}$ & $\mathrm{Y}$ & $\mathrm{Y}$ \\
\hline A1781 & $\mathrm{m}_{2}{ }^{6} \mathrm{~A}$ & Dim1 & $\mathrm{N}$ & $\mathrm{Y}$ & $\mathrm{Y}$ \\
\hline A1782 & $\mathrm{m}_{2}{ }^{6} \mathrm{~A}$ & Dim1 & $\mathrm{N}$ & $Y$ & $Y$ \\
\hline
\end{tabular}


bioRxiv preprint doi: https://doi.org/10.1101/2021.06.02.446812; this version posted June 2, 2021. The copyright holder for this preprint (which was not certified by peer review) is the author/funder, who has granted bioRxiv a license to display the preprint in perpetuity. It is made available under aCC-BY-ND 4.0 International license.

25S modificaitons (\# built/\# total: $\psi=27 / 30 ; \mathrm{N}_{\mathrm{m}}=36 / 37$; base modified $=5 / 7$ )

\begin{tabular}{|c|c|c|c|c|c|}
\hline Nucleotide & Modification & Enzyme/snoRNP & $\begin{array}{l}\text { Partial } \\
\text { (ref. 1) }\end{array}$ & $\begin{array}{l}\text { nopl- } \\
\text { D243A }\end{array}$ & $\begin{array}{l}c b f 5- \\
\text { D95A }\end{array}$ \\
\hline A645 & $\mathrm{m}^{1} \mathrm{~A}$ & Rrp8(Bmt1) & $\mathrm{N}$ & $\mathrm{Y}$ & $\mathrm{Y}$ \\
\hline A649 & $\mathrm{N}_{\mathrm{m}}$ & U18 & $\mathrm{N}$ & $\mathrm{Y}$ & $\mathrm{Y}$ \\
\hline C650 & $\mathrm{N}_{\mathrm{m}}$ & U18 & $\mathrm{N}$ & $\mathrm{Y}$ & $\mathrm{Y}$ \\
\hline C663 & $\mathrm{N}_{\mathrm{m}}$ & snR58 & $\mathrm{Y}$ & $\mathrm{Y}$ & $\mathrm{Y}$ \\
\hline U776 & $\Psi$ & snR80 & $\mathrm{N}$ & $\mathrm{Y}$ & $\mathrm{N}$ \\
\hline G805 & $\mathrm{N}_{\mathrm{m}}$ & snR39B & $\mathrm{N}$ & $\mathrm{Y}$ & $\mathrm{Y}$ \\
\hline A807 & $\mathrm{N}_{\mathrm{m}}$ & snR39/snR59 & $\mathrm{N}$ & $\mathrm{Y}$ & $\mathrm{Y}$ \\
\hline A817 & $\mathrm{N}_{\mathrm{m}}$ & snR60 & $\mathrm{N}$ & $\mathrm{Y}$ & $\mathrm{Y}$ \\
\hline G867 & $\mathrm{N}_{\mathrm{m}}$ & snR50 & $\mathrm{Y}$ & $\mathrm{Y}$ & $\mathrm{Y}$ \\
\hline A876 & $\mathrm{N}_{\mathrm{m}}$ & SNR72 & $\mathrm{Y}$ & $\mathrm{Y}$ & $\mathrm{Y}$ \\
\hline U898 & $\mathrm{N}_{\mathrm{m}}$ & snR40 & $\mathrm{N}$ & $\mathrm{Y}$ & $\mathrm{Y}$ \\
\hline G908 & $\mathrm{N}_{\mathrm{m}}$ & snR60 & $\mathrm{N}$ & $\mathrm{Y}$ & $\mathrm{Y}$ \\
\hline U956 & $\mathrm{m}^{3} \mathrm{U}$ & $\mathrm{Bmt5}$ & $\mathrm{N}$ & $\mathrm{N}^{*}$ & $\mathrm{~N}$ \\
\hline U960 & $\Psi$ & snR80 & $\mathrm{N}$ & $\mathrm{Y}$ & $\mathrm{N}$ \\
\hline U966 & $\Psi$ & snR43 & $\mathrm{N}$ & $\mathrm{Y}$ & $\mathrm{N}$ \\
\hline U986 & $\Psi$ & snR8 & $\mathrm{N}$ & $\mathrm{Y}$ & $\mathrm{N}$ \\
\hline U990 & $\Psi$ & snR49 & $\mathrm{N}$ & $\mathrm{Y}$ & $\mathrm{N}$ \\
\hline U1004 & $\Psi$ & snR5 & $\mathrm{Y}$ & $Y$ & $\mathrm{~N}$ \\
\hline U1042 & $\Psi$ & snR33 & $\mathrm{N}$ & $\mathrm{Y}$ & $\mathrm{N}$ \\
\hline U1052 & $\Psi$ & snR81 & $\mathrm{N}$ & $\mathrm{Y}$ & $\mathrm{N}$ \\
\hline U1056 & $\Psi$ & snR44 & $\mathrm{N}$ & $\mathrm{Y}$ & $\mathrm{N}$ \\
\hline U1110 & $\Psi$ & snR82 & $\mathrm{Y}$ & $\mathrm{Y}$ & $\mathrm{N}$ \\
\hline U1124 & $\Psi$ & snR5 & $\mathrm{N}$ & $Y$ & $\mathrm{~N}$ \\
\hline A1133 & $\mathrm{N}_{\mathrm{m}}$ & snR61 & $\mathrm{N}$ & $\mathrm{Y}$ & $\mathrm{Y}$ \\
\hline C1437 & $\mathrm{N}_{\mathrm{m}}$ & U24 & $\mathrm{N}$ & $\mathrm{Y}$ & $\mathrm{Y}$ \\
\hline A1449 & $\mathrm{N}_{\mathrm{m}}$ & U24 & $\mathrm{N}$ & $\mathrm{Y}$ & $\mathrm{Y}$ \\
\hline G1450 & $\mathrm{N}_{\mathrm{m}}$ & U24 & $\mathrm{N}$ & $\mathrm{Y}$ & $Y$ \\
\hline U1888 & $\mathrm{N}_{\mathrm{m}}$ & snR62 & $\mathrm{N}$ & $Y$ & $Y$ \\
\hline U2129 & $\Psi$ & SNR3 & $\mathrm{N}$ & $Y$ & $\mathrm{~N}$ \\
\hline U2133 & $\Psi$ & SNR3 & $\mathrm{N}$ & $Y$ & $\mathrm{~N}$ \\
\hline A2142 & $\mathrm{m}^{1} \mathrm{~A}$ & $\mathrm{Bmt2}$ & $\mathrm{N}$ & $\mathrm{Y}$ & $\mathrm{Y}$ \\
\hline U2191 & $\Psi$ & snR32 & $\mathrm{N}$ & $Y$ & $\mathrm{~N}$ \\
\hline C2197 & $\mathrm{N}_{\mathrm{m}}$ & snR76 & $\mathrm{N}$ & $\mathrm{Y}$ & $\mathrm{Y}$ \\
\hline A2220 & $\mathrm{N}_{\mathrm{m}}$ & snR47 & $\mathrm{N}$ & $\mathrm{Y}$ & $\mathrm{Y}$ \\
\hline A2256 & $\mathrm{N}_{\mathrm{m}}$ & snR63 & $\mathrm{N}$ & $\mathrm{N}^{*}$ & $\mathrm{~N}$ \\
\hline U2258 & $\Psi$ & snR191 & $\mathrm{N}$ & $\mathrm{N}^{*}$ & $\mathrm{~N}$ \\
\hline U2260 & $\Psi$ & snR191 & $\mathrm{N}$ & $\mathrm{N}^{*}$ & $\mathrm{~N}$ \\
\hline U2264 & $\Psi$ & snR3 & $\mathrm{N}$ & $\mathrm{Y}$ & $\mathrm{N}$ \\
\hline U2266 & $\Psi$ & snR84 & $\mathrm{N}$ & $\mathrm{N}^{*}$ & $\mathrm{~N}$ \\
\hline C2278 & $\mathrm{m}^{5} \mathrm{C}$ & $\mathrm{Rcm} 1(\mathrm{Bmt} 3)$ & $\mathrm{N}$ & $\mathrm{Y}$ & $\mathrm{Y}$ \\
\hline
\end{tabular}


bioRxiv preprint doi: https://doi.org/10.1101/2021.06.02.446812; this version posted June 2, 2021. The copyright holder for this preprint (which was not certified by peer review) is the author/funder, who has granted bioRxiv a license to display the preprint in perpetuity. It is made

\begin{tabular}{|c|c|c|c|c|c|}
\hline \\
\hline A2280 & $\mathrm{N}_{\mathrm{m}}$ & snR13 & $\mathrm{N}$ & Y & Y \\
\hline A2281 & $\mathrm{N}_{\mathrm{m}}$ & snR13 & $\mathrm{N}$ & Y & Y \\
\hline A2288 & $\mathrm{N}_{\mathrm{m}}$ & snR75 & $\mathrm{N}$ & $\mathrm{Y}$ & $\mathrm{Y}$ \\
\hline U2314 & $\Psi$ & snR86 & $\mathrm{N}$ & $\mathrm{Y}$ & $\mathrm{N}$ \\
\hline $\mathrm{C} 2337$ & $\mathrm{~N}_{\mathrm{m}}$ & snR64 & $\mathrm{N}$ & $\mathrm{Y}$ & $\mathrm{Y}$ \\
\hline U2340 & $\Psi$ & snR9 & $\mathrm{N}$ & Y & $\mathrm{N}$ \\
\hline U2347 & $\Psi / \mathrm{N}_{\mathrm{m}}$ & snR65/snR9 & $\mathrm{N}$ & Y & $\mathrm{N}_{\mathrm{m}}$ \\
\hline U2349 & $\Psi$ & snR82 & $\mathrm{N}$ & $\mathrm{Y}$ & $\mathrm{N}$ \\
\hline U2416 & $\Psi$ & snR11 & $\mathrm{N}$ & $\mathrm{Y}$ & $\mathrm{N}$ \\
\hline U2417 & $\mathrm{N}_{\mathrm{m}}$ & snR66 & $\mathrm{N}$ & $\mathrm{Y}$ & $\mathrm{Y}$ \\
\hline U2421 & $\mathrm{N}_{\mathrm{m}}$ & snR78 & $\mathrm{N}$ & $\mathrm{Y}$ & $\mathrm{Y}$ \\
\hline G2619 & $\mathrm{N}_{\mathrm{m}}$ & snR78 & $\mathrm{N}$ & $\mathrm{Y}$ & $\mathrm{Y}$ \\
\hline U2634 & $\mathrm{m}^{3} \mathrm{U}$ & Bmt5 & $\mathrm{N}$ & Y & Y \\
\hline A2640 & $\mathrm{N}_{\mathrm{m}}$ & snR68 & $\mathrm{N}$ & Y & Y \\
\hline U2724 & $\mathrm{N}_{\mathrm{m}}$ & snR67 & $\mathrm{N}$ & $\mathrm{Y}$ & $\mathrm{Y}$ \\
\hline U2729 & $\mathrm{N}_{\mathrm{m}}$ & snR51 & $\mathrm{Y}$ & $\mathrm{Y}$ & $\mathrm{Y}$ \\
\hline U2735 & $\Psi$ & snR189 & $\mathrm{N}$ & $\mathrm{Y}$ & $\mathrm{N}$ \\
\hline G2791 & $\mathrm{N}_{\mathrm{m}}$ & snR48 & $\mathrm{N}$ & $\mathrm{Y}$ & $\mathrm{Y}$ \\
\hline G2793 & $\mathrm{N}_{\mathrm{m}}$ & snR48 & $\mathrm{N}$ & Y & $\mathrm{Y}$ \\
\hline G2815 & $\mathrm{N}_{\mathrm{m}}$ & snR38 & $\mathrm{N}$ & $\mathrm{Y}$ & Y \\
\hline U2826 & $\Psi$ & Snr34 & $\mathrm{N}$ & $\mathrm{Y}$ & $\mathrm{N}$ \\
\hline U2843 & $\mathrm{m}^{3} \mathrm{U}$ & Bmt6 & $\mathrm{N}$ & $\mathrm{N}^{*}$ & $\mathrm{~N}$ \\
\hline U2865 & $\Psi$ & snR46 & $\mathrm{N}$ & $\mathrm{Y}$ & $\mathrm{N}$ \\
\hline $\mathrm{C} 2870$ & $\mathrm{~m}^{5} \mathrm{C}$ & Nop2/Bmt4 & $\mathrm{N}$ & Y & Y \\
\hline U2880 & $\Psi$ & snR34 & $\mathrm{N}$ & $\mathrm{Y}$ & $\mathrm{N}$ \\
\hline U2921 & $\mathrm{N}_{\mathrm{m}}$ & snR52/Sbp1 & $\mathrm{N}$ & $\mathrm{Y}$ & $\mathrm{Y}$ \\
\hline G2922 & $\mathrm{N}_{\mathrm{m}}$ & Sbp1 & $\mathrm{N}$ & $\mathrm{Y}$ & Y \\
\hline U2923 & $\Psi$ & snR10 & $\mathrm{N}$ & $\mathrm{Y}$ & $\mathrm{N}$ \\
\hline U2944 & $\Psi$ & snR37 & $\mathrm{N}$ & $\mathrm{Y}$ & $\mathrm{N}$ \\
\hline A2946 & $\mathrm{N}_{\mathrm{m}}$ & snR71 & $\mathrm{N}$ & $\mathrm{Y}$ & $\mathrm{Y}$ \\
\hline C2948 & $\mathrm{N}_{\mathrm{m}}$ & snR69 & $\mathrm{N}$ & Y & $\mathrm{Y}$ \\
\hline $\mathrm{C} 2959$ & $\mathrm{~N}_{\mathrm{m}}$ & snR73 & $\mathrm{N}$ & Y & Y \\
\hline U2975 & $\Psi$ & snR42 & $\mathrm{N}$ & $\mathrm{Y}$ & $\mathrm{N}$ \\
\hline
\end{tabular}

5.8S modifications (\# built/\# total: $\psi=0 / 1$ )

\begin{tabular}{|l|l|l|l|l|l|}
\hline U73 & $\Psi$ & snR43 & Y & Y & $\mathrm{N}^{*}$ \\
\hline
\end{tabular}

5 S modifications (\# built/\# total: $\psi=0 / 1$ )

\begin{tabular}{|l|l|l|l|l|l|}
\hline U50 & Y & Pus57 & N & Y & $\mathrm{N}^{*}$ \\
\hline
\end{tabular}

Protein modifications

\begin{tabular}{|l|l|l|l|l|l|}
\hline Protein & Modificaiton & Enzyme & $\begin{array}{l}\text { Partial } \\
\text { (ref. 1) }\end{array}$ & $\begin{array}{l}\text { nopl- } \\
\text { D243A }\end{array}$ & $\begin{array}{l}c b f 5- \\
\text { D95A }\end{array}$ \\
\hline rpL3/H243 & 3-MH & Hpm1 methyltransferase & NA & Y & Y \\
\hline
\end{tabular}

\#3-amino-3-carboxypropyl was built for the cbf5-D95A ribosome; *either bad density or insufficient feature to build. 
bioRxiv preprint doi: https://doi.org/10.1101/2021.06.02.446812; this version posted June 2, 2021. The copyright holder for this preprint (which was not certified by peer review) is the author/funder, who has granted bioRxiv a license to display the preprint in perpetuity. It is made available under aCC-BY-ND 4.0 International license.

Supplementary Table 2. Data Acquisition, Processing and Model Refinement

\begin{tabular}{|c|c|c|}
\hline $\begin{array}{l}\text { Data acquisition \& processing } \\
\text { parameters }\end{array}$ & nop1-D243A & cbf5-D95A \\
\hline Microscope & Titan Krios & Titan Krios \\
\hline Detector & Gatan K3 & Gatan K3 \\
\hline Voltage & $300 \mathrm{kV}$ & $300 \mathrm{kV}$ \\
\hline Electron Source & Field Emission Gun & Field Emission Gun \\
\hline Collecting Mode & Counting & Counting \\
\hline Dose Rate $\left(\mathrm{e}^{-} / \AA^{2}\right)$ & 60.07 & 60.07 \\
\hline Defocus range $(\mu \mathrm{m})$ & -1.3 to -2.5 & -1.3 to -2.5 \\
\hline Nominal Magnification & $81000 X$ & $81000 \mathrm{X}$ \\
\hline Frames collected per exposure & 70 & 74 \\
\hline Framealingment Software & MotionCor2 & MotionCor2 \\
\hline CTF parameter estimation & Gctf & Gctf \\
\hline Total number of raw images collected & 6,460 & 6,358 \\
\hline $\begin{array}{l}\text { Number of images used for particle } \\
\text { picking }\end{array}$ & 4,962 & 5,800 \\
\hline Initial particles picked & 695,940 & 726,857 \\
\hline 2D classification software & Relion 3.1 & Cryosparc \\
\hline Final reconstruction software & Relion 3.1 & Relion 3.1 \\
\hline Applied symmetry & C1 & C1 \\
\hline $\begin{array}{l}\text { Number of particles contributed for the } \\
\text { final reconstruction }\end{array}$ & $\begin{array}{l}288,240(60 S) \\
289,345(40 S)\end{array}$ & $\begin{array}{l}404,065(60 S) \\
349,046(40 S)\end{array}$ \\
\hline Resolution method & FSC 0.143 cut-off & FSC 0.143 cut-off \\
\hline Map resolution $(\AA)$ & $\begin{array}{l}2.57 \AA \text { (60S) } \\
2.72 \AA \text { (40S-head) } \\
2.72 \AA \text { (40S-body) }\end{array}$ & $\begin{array}{l}2.89 \AA \text { (60S) } \\
3.03 \AA \text { (40S-head) } \\
2.99 \AA \text { (40S-body) }\end{array}$ \\
\hline Local resolution determining Software & Resmap & Resmap \\
\hline Map Visualization software & $\begin{array}{l}\text { Pymol/Chimera/ } \\
\text { Chimera X/ Coot }\end{array}$ & $\begin{array}{l}\text { Pymol/Chimera/ } \\
\text { Chimera X/ Coot }\end{array}$ \\
\hline Deposit EMDB codes & 23935 & 23934 \\
\hline \multicolumn{3}{|l|}{ Refinement parameters } \\
\hline CC (map_model) & $\begin{array}{l}0.78 \text { (mask), } 0.81 \\
\text { (volume) }\end{array}$ & $\begin{array}{l}0.78 \text { (mask), } 0.82 \\
\text { (volume) }\end{array}$ \\
\hline RMSD (Bond lengths/Bond angles) & $0.012 / 1.222$ & $0.009 / 1.096$ \\
\hline $\begin{array}{l}\text { Ramachandran plot (\%) } \\
\text { (Outlier/Allowed/Favored) }\end{array}$ & $0.45 / 7.81 / 91.74$ & $0.3 / 8.25 / 91.35$ \\
\hline $\mathrm{C} \beta$ Outliers (\%) & 0.03 & 0.02 \\
\hline MolProbity Score & 1.71 & 1.81 \\
\hline Clash score & 4.29 & 5.52 \\
\hline Rotamer outliers (\%) & 0.05 & 0.03 \\
\hline $\begin{array}{l}\text { ADP (B-factor) } \\
\text { Protein (min/max/mean) } \\
\text { Nucleotide (min/max/mean) } \\
\text { Ligand (min/max/mean) }\end{array}$ & $\begin{array}{l}199811 \\
2.57 / 32.30 / 15.34 \\
4.62 / 61.43 / 19.14 \\
5.63 / 40.73 / 12.89 \\
\end{array}$ & $\begin{array}{l}199433 \\
9.42 / 104.99 / 40.21 \\
6.07 / 183.35 / 49.97 \\
7.44 / 110.30 / 31.20\end{array}$ \\
\hline dFSC model $(0.5)$ & 2.7 & 2.9 \\
\hline Deposit PDB codes & 7MPJ & 7MPI \\
\hline
\end{tabular}




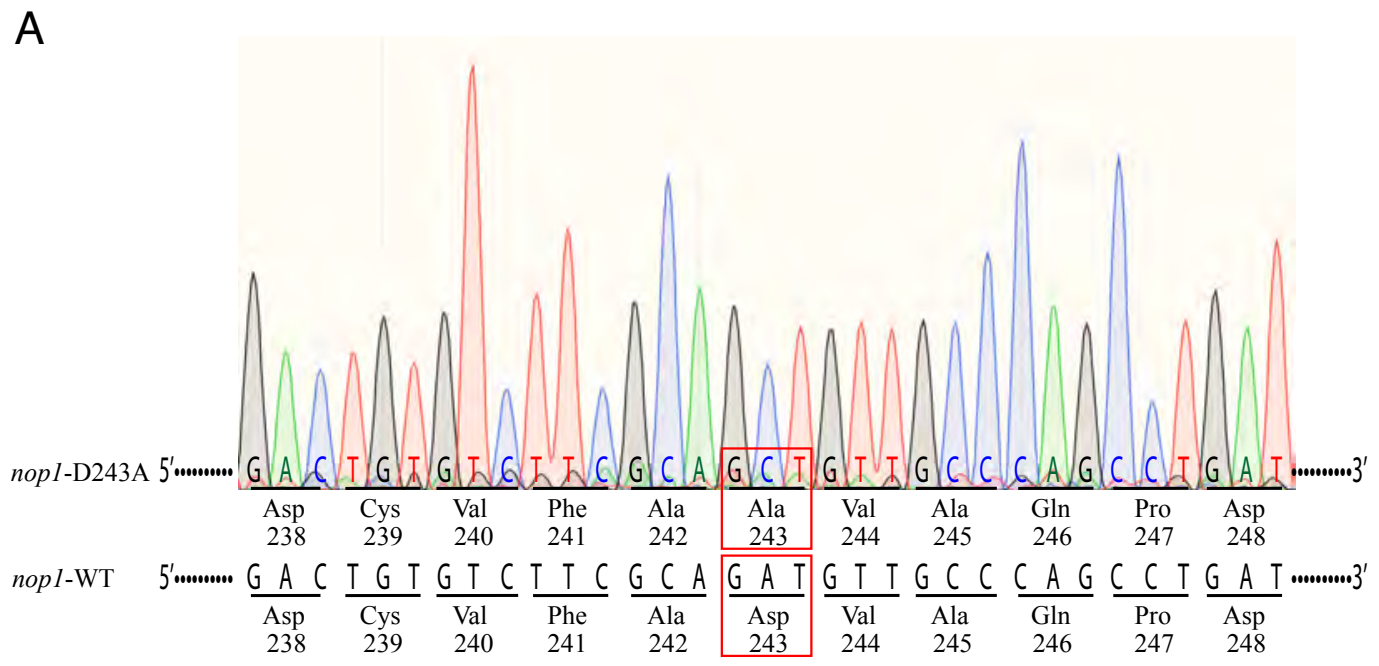

B

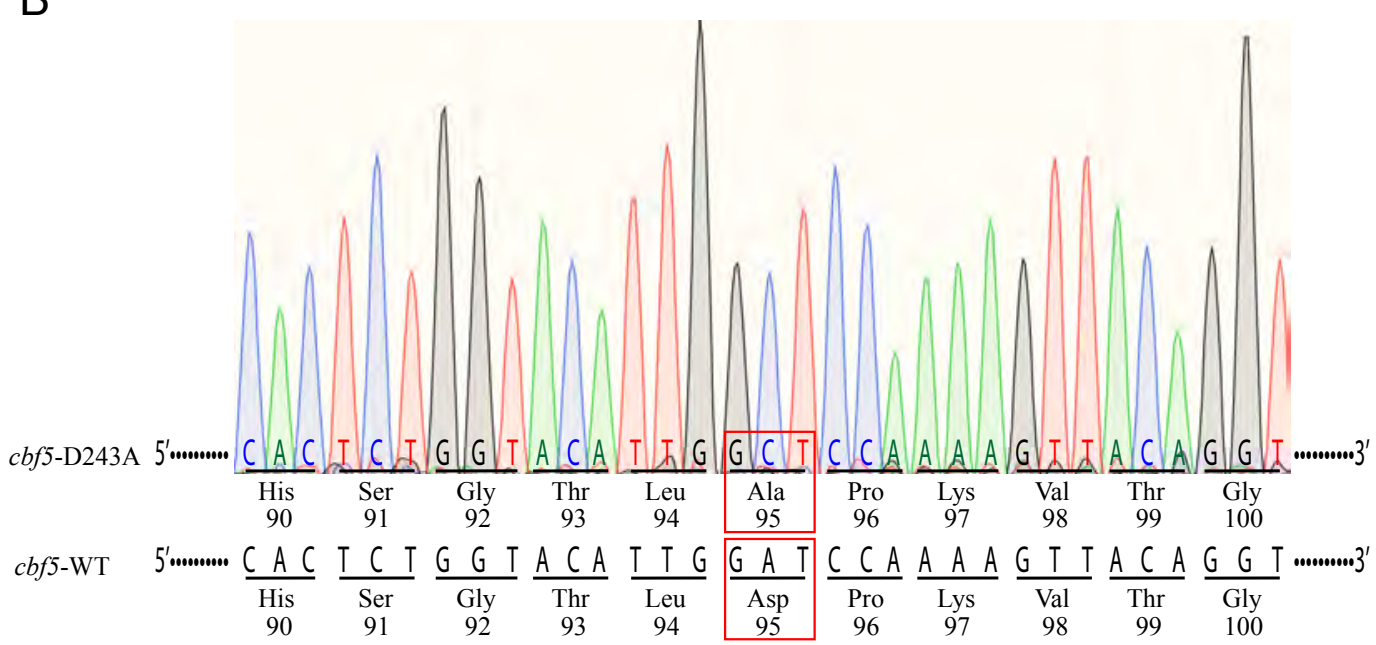

Supplementary Figure 1. Related to Figures 1, 2, 3, \& 4. Sanger sequencing verification of the cbf5-D95A (A) and nop1-D243A (B) mutations. Interpreted bases from chromatograms are shown in colored letters. Corresponding codons are underscored and the encoded amino acids are show as three-letter symbols. The wild-type sequences of the same regions are shown in black. Point mutations are highlighted with red boxes. 
bioRxiv preprint doi: https://doi.org/10.1101/2021.06.02.446812; this version posted June 2, 2021. The copyright holder for this preprint (which was not certified by peer review) is the author/funder, who has granted bioRxiv a license to display the preprint in perpetuity. It is made available under aCC-BY-ND 4.0 International license.

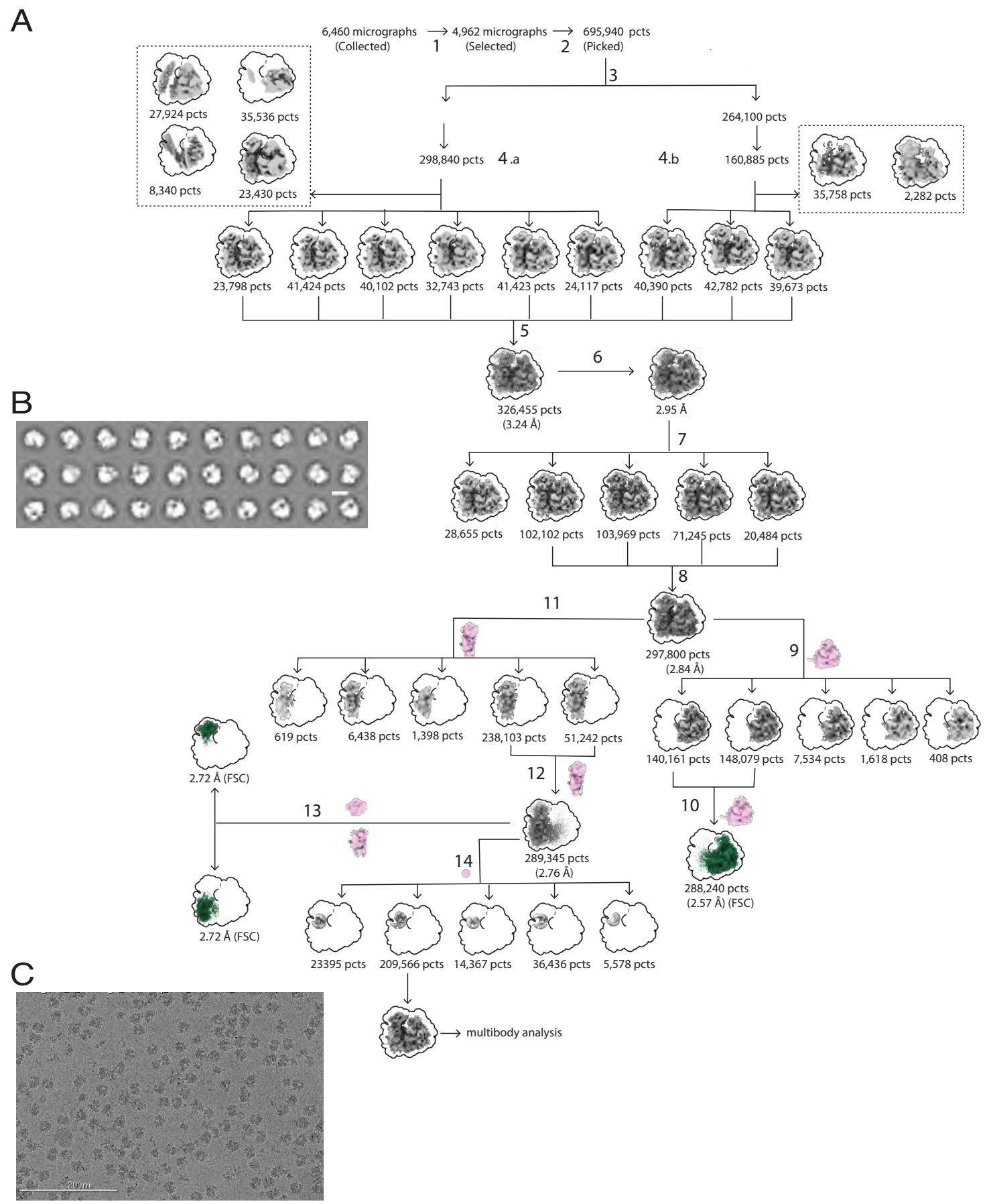

D

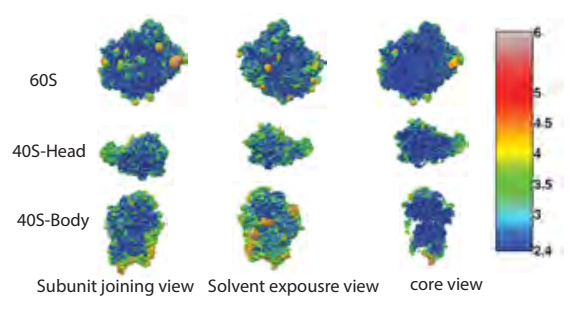

$E$

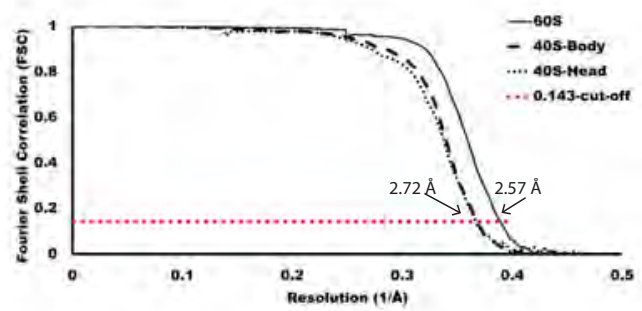


bioRxiv preprint doi: https://doi.org/10.1101/2021.06.02.446812; this version posted June 2, 2021. The copyright holder for this preprint (which was not certified by peer review) is the author/funder, who has granted bioRxiv a license to display the preprint in perpetuity. It is made available under aCC-BY-ND 4.0 International license.

Supplementary Figure 2. Related to Figures 2, 3, \& 4. Cryo-EM image analysis flow chart of nop 1-D243A ribosome. A. Image selection, particle selection, and recontruction schemes. Masks used in focused classification and refinement are shown in pink and at each relevant path junction. The final maps used for model building and refinement are shown in blue. A final of 4,962 images were selected for further processing (1) and a total of 695,940 particles (pcts) were picked (3), extracted in bin 4, and split arbitrarily into two halves. The first half contained 431,895 pcts which were reduced to 298,840 pcts after 2D classification (4.a). The other half contained 264,100 pcts which was reduced to 160,885 pcts after 2D classification (4.b). Particles with bad features shown in dash line boxes were removed. 3D classification of the two half particles resulted in a total of 326,455 pcts that were reextracted in bin 1 (unbinned) and refined to $3.24 \AA$ (5). Contrast Transfer Function (CTF) refinement improved the overall resolution to 2.95 A (6). Further classifification without alignment allowed additional selection of particles (7) for refinment and particle polishing, which led to an overall resolution of $2.84 \AA$ (8). To improve the $60 \mathrm{~S}$ density, particles were further classified without alignment into five classes using a 3D custom mask on the 60S subunit region (9). The classes with good 60S density were pooled together and again refined using a custom3D mask around the $60 \mathrm{~S}$ subunits that resulted in an overall resolution of $2.57 \AA$ for the $60 \mathrm{~S}$ region (10). To improve the 40S density, particles from step 8 were classified without alignment into five classes using the 3D custom mask on the $40 \mathrm{~S}$ subunit region (11). The classes with good $40 \mathrm{~S}$ density were pooled and rerefined using a 3D mask around the $40 \mathrm{~S}$ region that resulted in an overall resolution of $2.76 \AA$ resolution around the $40 \mathrm{~S}$ region(12). The particles were further refined using a mask around the head and body of the 40S that improved the resolution of head and body to $2.72 \AA$ for both regions (13). To select Stm1-bound ribosome, focused 3D classification was performed using a spherical mask around the mRNA entry channel, which led to a major class with 209,566 particles that showed good Stm1 density and was, therefore, used for multibody analysis (14). B. Selected 2D class averages (scale bar 20nm). C. A representative raw micrograph (scale bar $200 \mathrm{~nm}$ ). D. Local resolution estimated by Resmap showing the comparably high-resolution inner core. E. The Fourier Shell Correlation (FSC) curves of $80 \mathrm{~S}, 40 \mathrm{~S}$ body, $40 \mathrm{~S}$ head and 60S. 0.143 cutoff was used for resolution estimatimation. 
bioRxiv preprint doi: https://doi.org/10.1101/2021.06.02.446812; this version posted June 2, 2021. The copyright holder for this preprint (which was not certified by peer review) is the author/funder, who has granted bioRxiv a license to display the preprint in perpetuity. It is made available under aCC-BY-ND 4.0 International license.

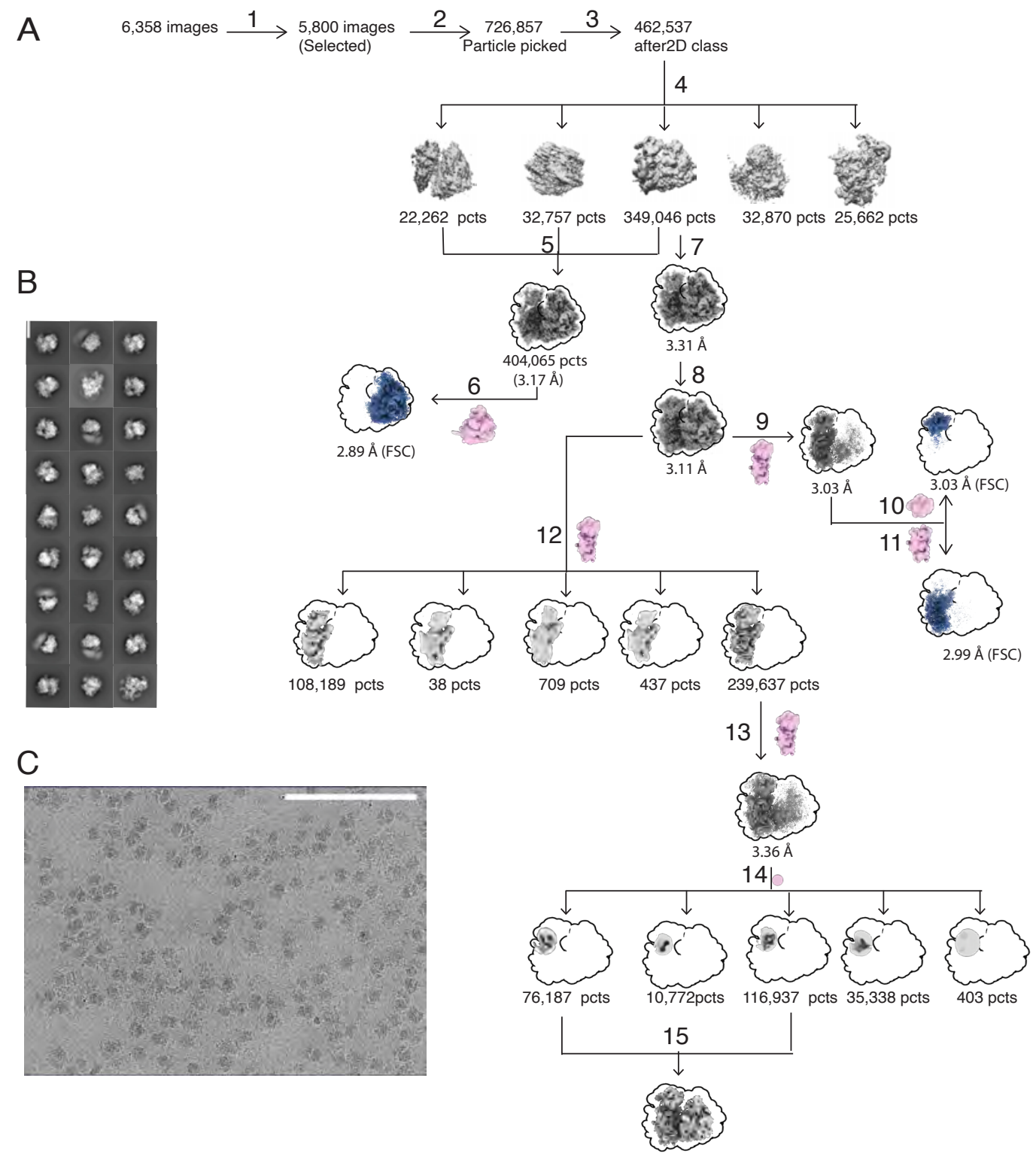

$\mathrm{D}$

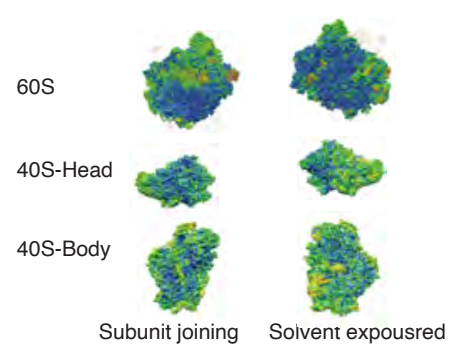

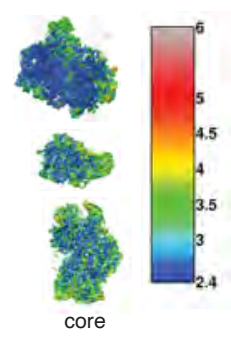

E

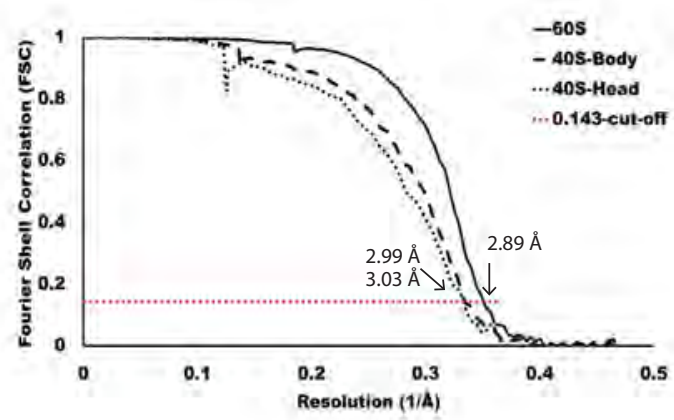


bioRxiv preprint doi: https://doi.org/10.1101/2021.06.02.446812; this version posted June 2, 2021. The copyright holder for this preprint (which was not certified by peer review) is the author/funder, who has granted bioRxiv a license to display the preprint in perpetuity. It is made available under aCC-BY-ND 4.0 International license.

Supplementary Figure 3. Related to Figures 2, 3, \& 4. Cryo-EM image analysis flow chart of cbf5-D95A. A. Image selection, particle selection, and recontruction schemes. Masks used in focused classification and refinement are shown in pink and at each relevant path junction. The final maps used for model building and refinement are shown in blue. A final of 5800 images were selected for further processing (1) and a total of 726,857 particles (pcts) were picked in RELION 3.1 (2). 2D classifications and selection in cryosparc reduced the particles to 462,537 (3) that were 3D classified into five classes (4). To obtain the best $60 \mathrm{~S}$ structure, three classes were combined and refined to 3.17 $\AA$ in RELION 3.1 (5). After per-particle Contrast Transfer Function (CTF) refinement using the custom mask around the $60 \mathrm{~S}$ subunit improved the $60 \mathrm{~S}$ resolution to $2.89 \AA$ (6). To obtain the best 40S resolution, a single dominant class (349,046 pcts) was refined to 3.31 Å resolution (7) which was further improved to $3.11 \AA$ after per particles CTF refinement (8). Using a custom 3D mask on the 40S subunit during refinement yielded the overall 40S subunit resolution to $3.03 \AA$ (9) that was further improved for the body and head region to $3.03 \AA$ (10) and $2.99 \AA$ (11) and $3.03 \AA$ with their respective masks. To ensure multibody analysis was performed on Stm1-bound ribosome, particles with good 40S density were further classified into five classes without alignment using the 40S custom mask (12). The predominant class (239,637 pcts) showed good 40S subunit density and refined using a custom 3D mask on 40S subunit (13) followed by another round of 3D classification based on Stm1 using a spherical mask around the mRNA entry channel (14). Two classes show clear Stm1 density and hence pooled together (15). B. Selected 2D class averages (scale bar 20nm). C. A representative raw micrograph (scale bar $200 \mathrm{~nm}$ ). D. Local resolution estimated by Resmap showing the comparably high-resolution inner core. E. The Fourier Shell Correlation (FSC) curves of 80S, 40S body, 40S head and 60S. 0.143 cutoff was used for resolution estimatimation. 
bioRxiv preprint doi: https://doi.org/10.1101/2021.06.02.446812; this version posted June 2, 2021. The copyright holder for this preprint (which was not certified by peer review) is the author/funder, who has granted bioRxiv a license to display the preprint in perpetuity. It is made available under aCC-BY-ND 4.0 International license.
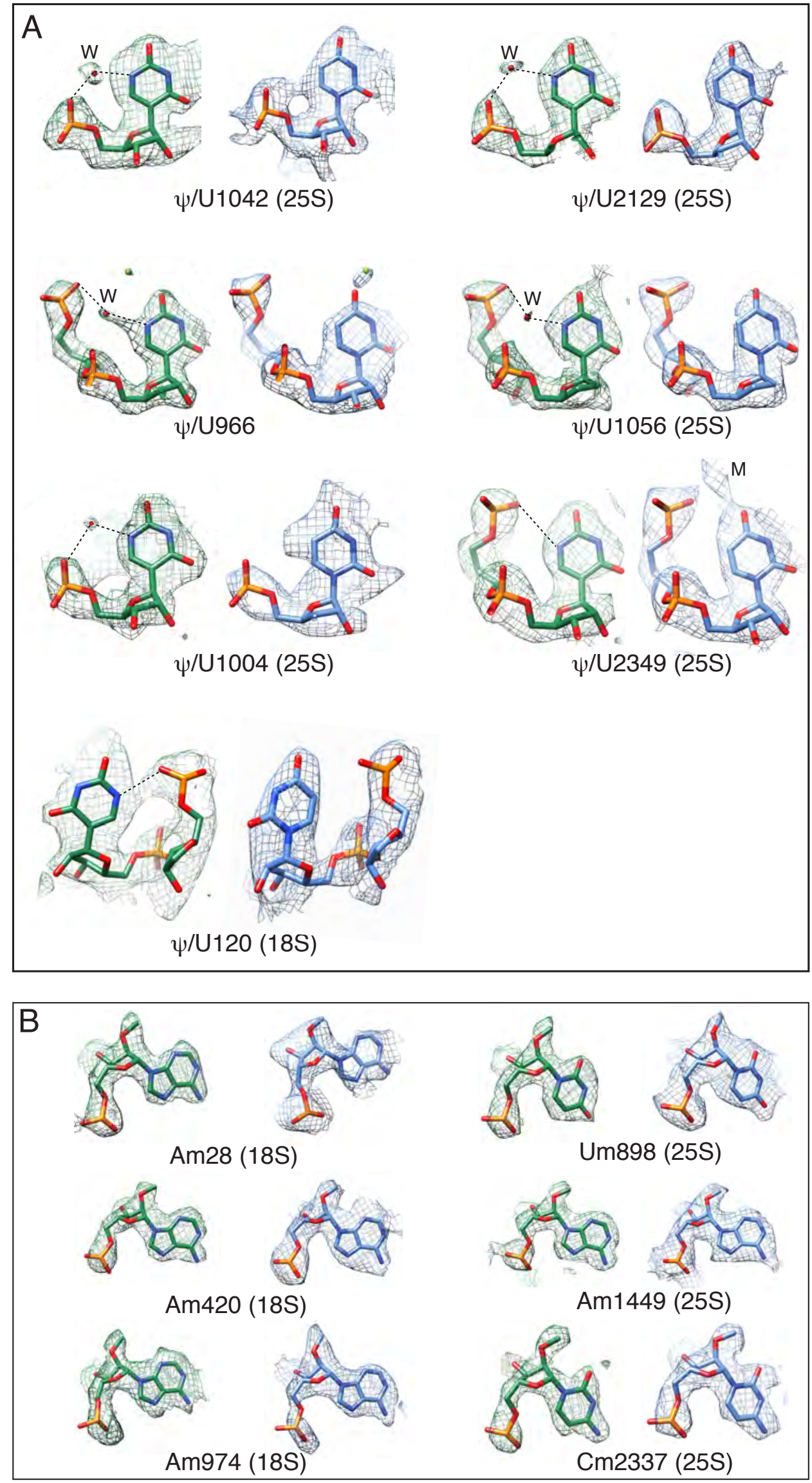

nop1-D243A

cbf5-D95A 
bioRxiv preprint doi: https://doi.org/10.1101/2021.06.02.446812; this version posted June 2, 2021. The copyright holder for this preprint (which was not certified by peer review) is the author/funder, who has granted bioRxiv a license to display the preprint in perpetuity. It is made

Supplementary Figure 4. Related to Figures 2, 3, \& 4. Electron potential density for selected nucloetides that are predicted to be pseudouridylated (A) or 2'-O-methylated (B). Nucleotides colored in green are those from the nop1-D243A ribosome and those colored in blue from from the $c b f 5$-D95A ribosome. " $\mathrm{W}$ " denotes a potential water molecule and " $\mathrm{M}$ " denote a potential metal ion. Dashed lines denote close contacts. 


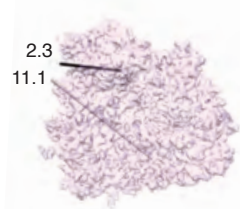

$3 \mathrm{~J} 78$ vs $3 \mathrm{~J} 77$

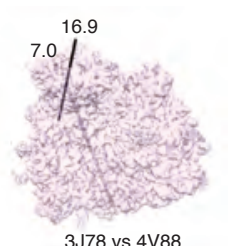

$3 \mathrm{~J} 78$ vs $4 \mathrm{~V} 88$

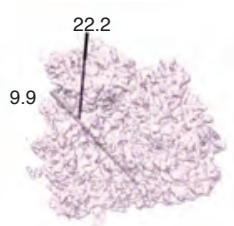

$3 \mathrm{~J} 78$ vs 4 V7R

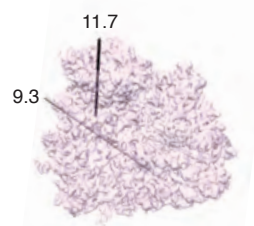

$3 \mathrm{~J} 78$ vs $5 \mathrm{JUO}$

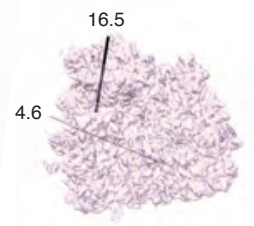

$3 J 78$ vs $5 J U S$

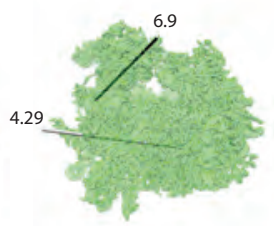

$4 \mathrm{~V} 88$ vs $4 \mathrm{~V} 7 \mathrm{R}$

head $\quad$ body

Supplementary Figure 5. Related to Figure 3. Comparison of known ribosome conformations. For each compared ribosome, Protein Data Bank (PDB) code is given. Numers indicate degrees of rotation in clockwise direction when viewed into each axis. The cryoEM maps (or model converted maps) were used to compute their relative motion with respect to the non-rotated state (PDB ID: 3J78, pink) or between the two Stm1-bound ribosome (green). The relationship between the two compared heads is indicated by the location and degree of rotation of the rotation axis in black (swivel). The relationship between the two compared bodies is indicated by the location and degree of rotation of the rotation axis in gray (ratchet). 
bioRxiv preprint doi: https://doi.org/10.1101/2021.06.02.446812; this version posted June 2, 2021. The copyright holder for this preprint (which was not certified by peer review) is the author/funder, who has granted bioRxiv a license to display the preprint in perpetuity. It is made available under aCC-BY-ND 4.0 International license.
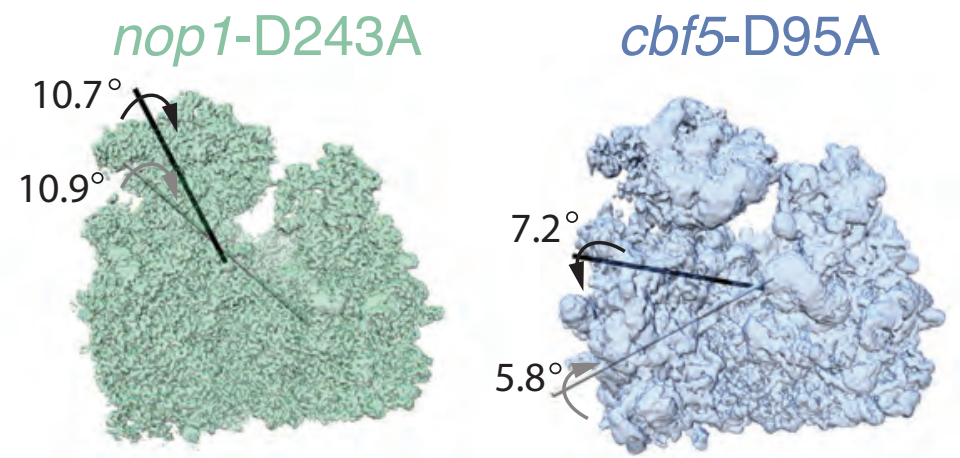

Eigenvalue 1
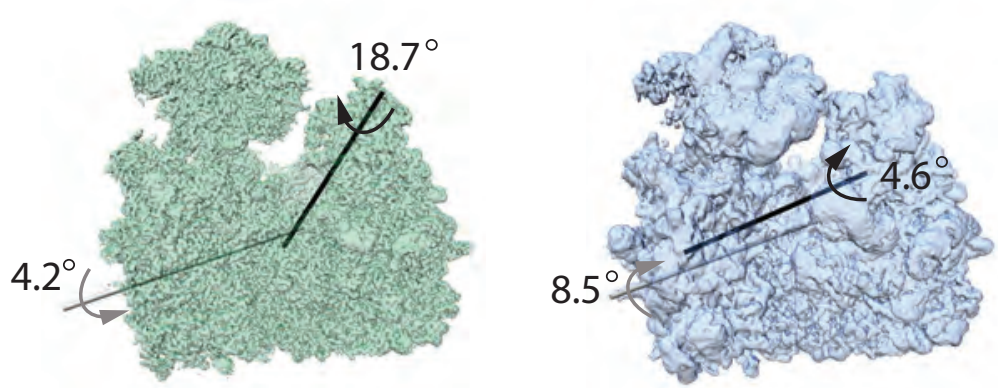

Eigenvalue 2
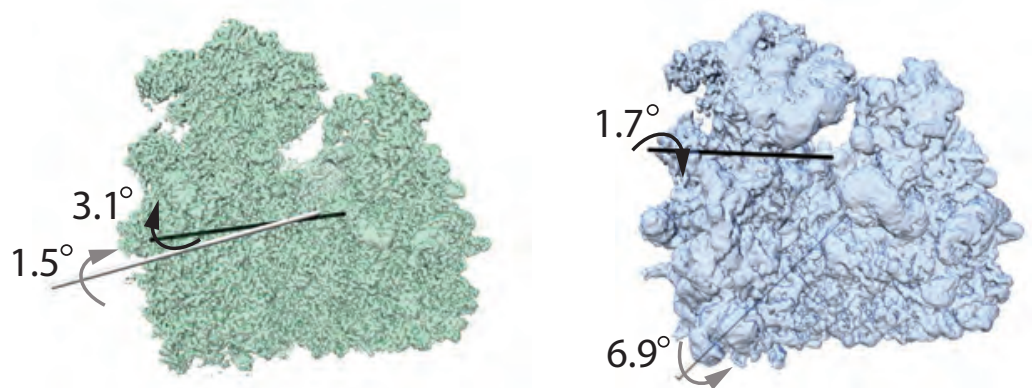

Eigenvalue 3

head

body

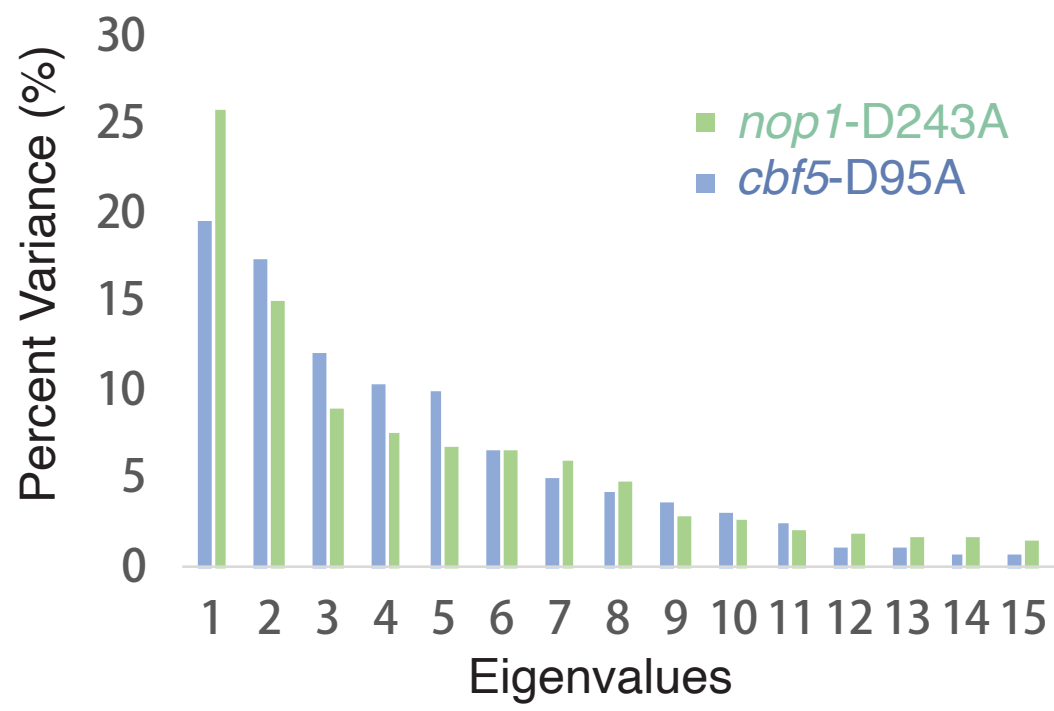


bioRxiv preprint doi: https://doi.org/10.1101/2021.06.02.446812; this version posted June 2, 2021. The copyright holder for this preprint (which was not certified by peer review) is the author/funder, who has granted bioRxiv a license to display the preprint in perpetuity. It is made

Supplementary Figure 6. Related to Figure 3. 3D multivaribilty analysis for the nop1-D243A (green) and cbf5-D95A (blue) ribosome. Top, electron potential densities representing the two extreme amplitude values of top 3 eigenvectors are compared. For each eigenvector, the two extreme maps were superimposed to a reference $60 \mathrm{~S}$ density in order for the rotation axis that brings the $40 \mathrm{~S}$ body of one map to that of another map to be calculated. The two maps were then superimposed to a reference map of the $40 \mathrm{~S}$ body for the rotation axis that brings the $40 \mathrm{~S}$ head of one map to that of another map to be calculated. The arrows indicate the direction of rotation while the numbers indicate the degree of rotation. Bottom, percent variance plot for the top 15 eigenvectors for the nop 1-D243A (green) and $c b f 5$-D95A (blue) ribosome. 
bioRxiv preprint doi: https://doi.org/10.1101/2021.06.02.446812; this version posted June 2, 2021. The copyright holder for this preprint (which was not certified by peer review) is the author/funder, who has granted bioRxiv a license to display the preprint in perpetuity. It is made available under aCC-BY-ND 4.0 International license.

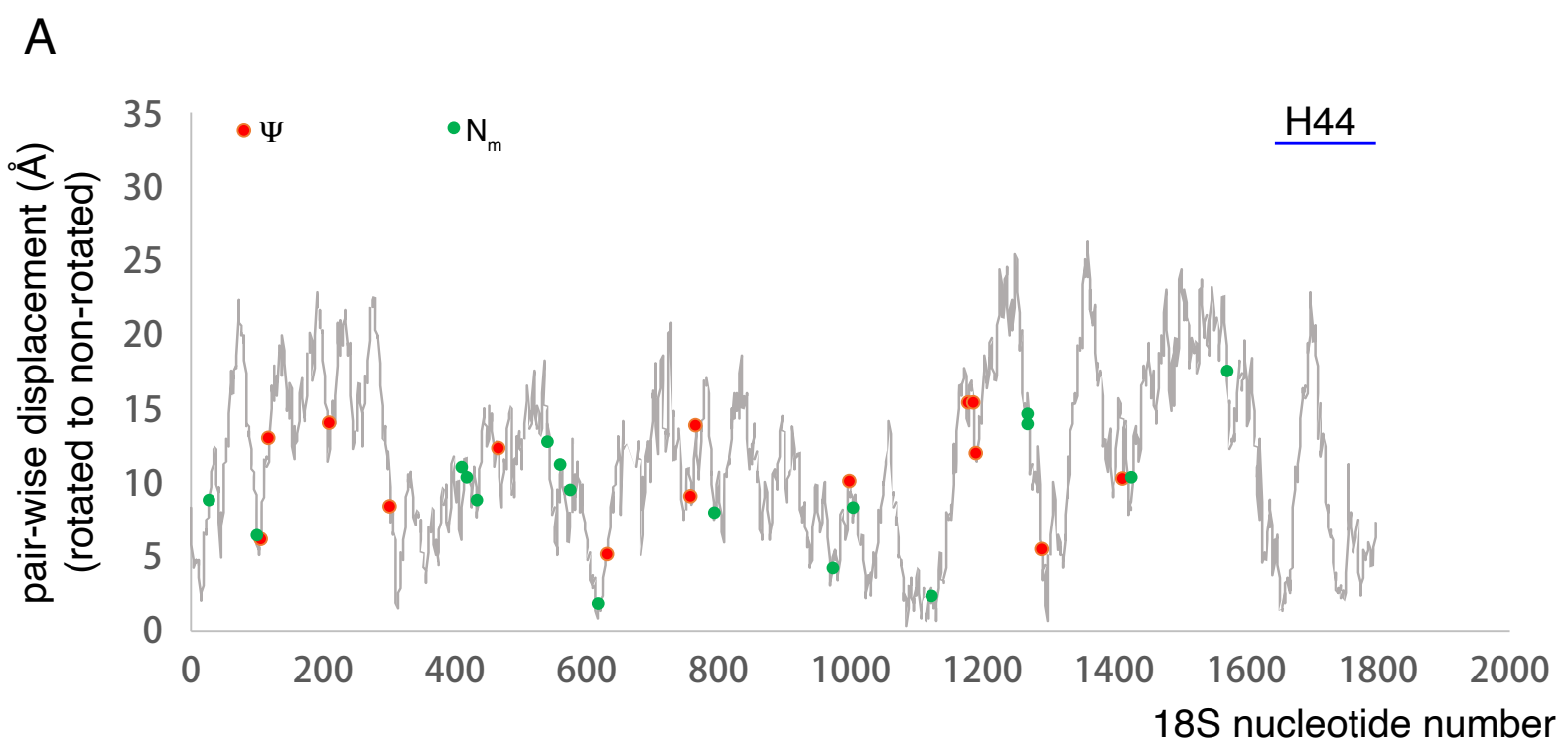

B

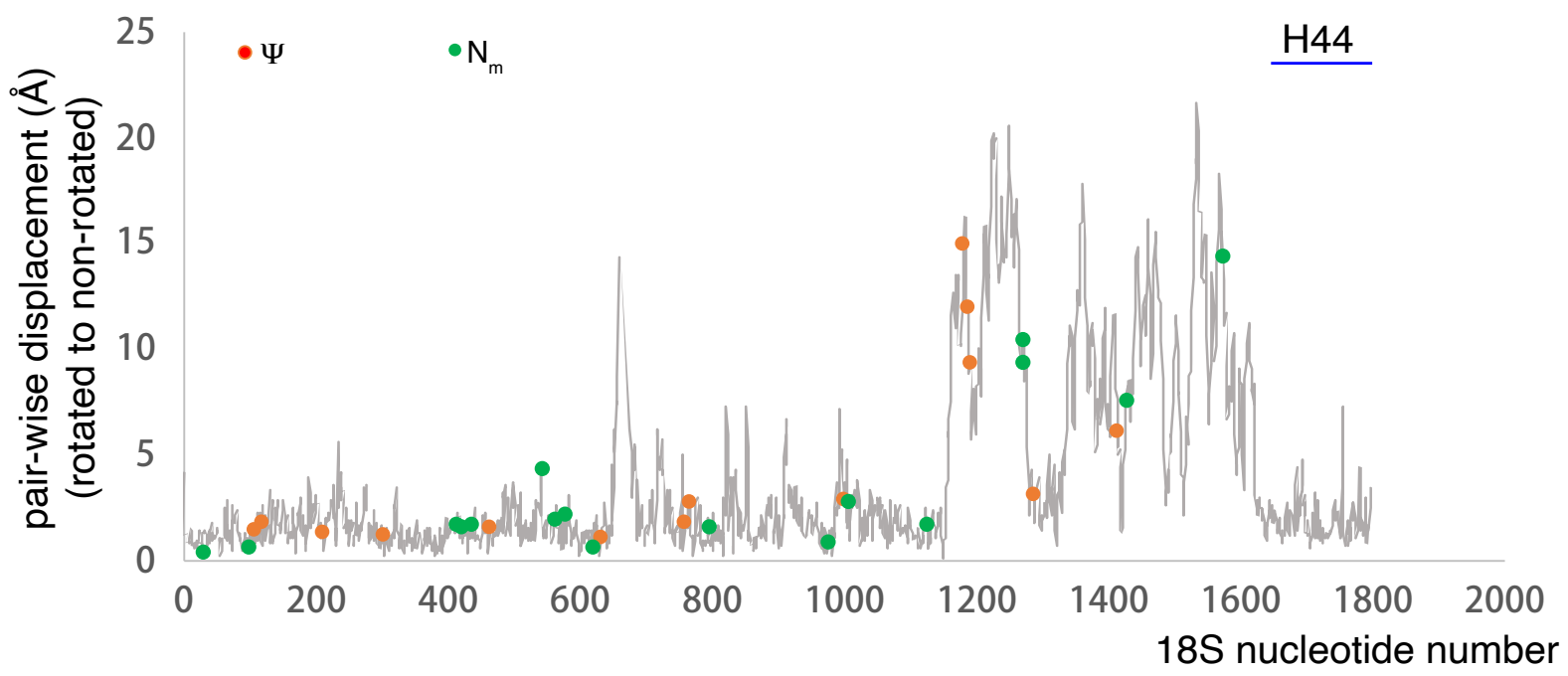

C
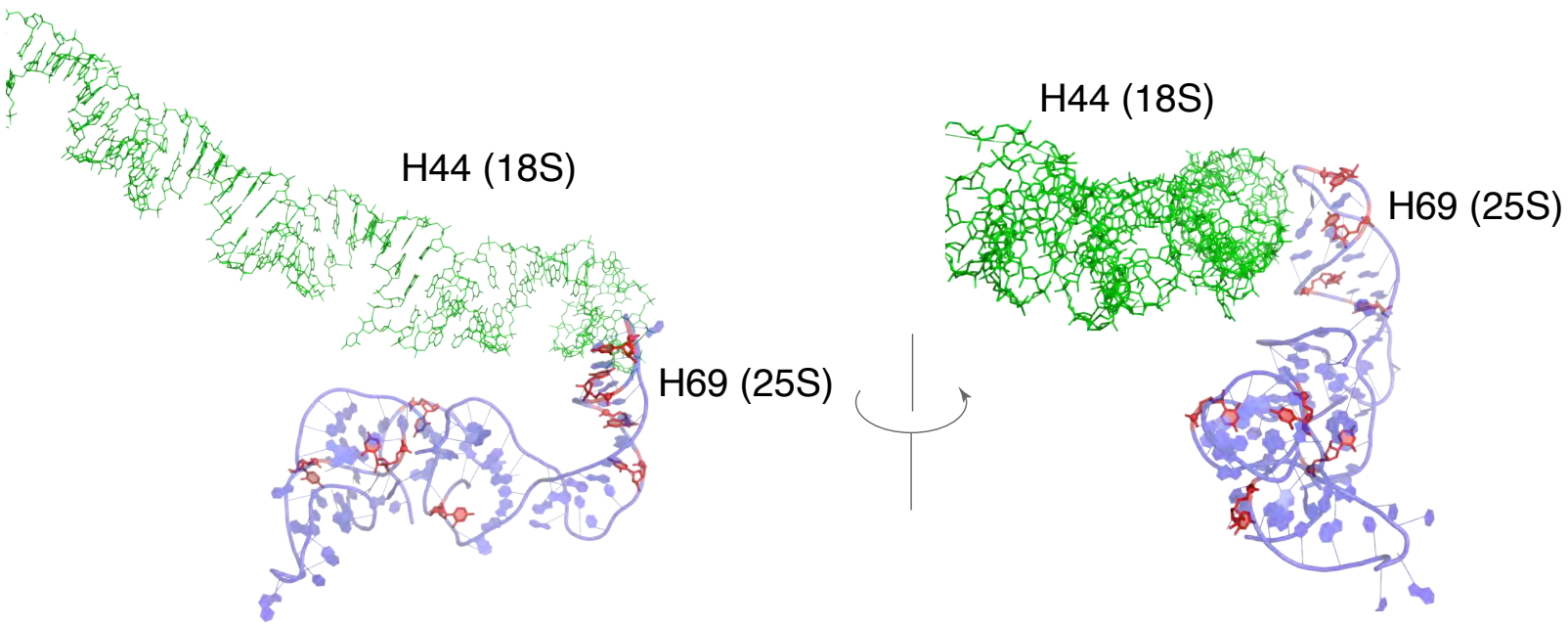
bioRxiv preprint doi: https://doi.org/10.1101/2021.06.02.446812; this version posted June 2, 2021. The copyright holder for this preprint (which was not certified by peer review) is the author/funder, who has granted bioRxiv a license to display the preprint in perpetuity. It is made

Supplementary Figure 7. Related to Figure 4. Mapping modification sites on the nucleotide pair-wise displacement plot for the small subunit ribosomal RNA (18S rRNA) when transforming the rotated (PDB ID: 3J77) to the non-rotated (PDB ID: 3J78) ribosome conformation. Red spheres indication positions of pseudouridine while green spheres indicate the positions of 2'-O-methylated nucloetides. The location of helix $\mathrm{H} 44$ is indicated by a blue bar. A. Pair-wise displacement between 3J77 and 3J78 185 nucleotides when their $25 \mathrm{~S}$ rRNA are aligned. B. Pair-wise displacement between 3J77 and 3J78 $18 \mathrm{~S}$ nucleotides when the body porsion of their 18S rRNA are aligned. C. Illustration of interactions between helix H44 of $18 \mathrm{~S}$ (green) with a pseudouridine-rich helix H69 at the intersubunit bidge region of 25S (blue). H44 nucleotides are shawn as sticks models while H69 is shown as cartoon models. Pseodouridine is colored in red. 

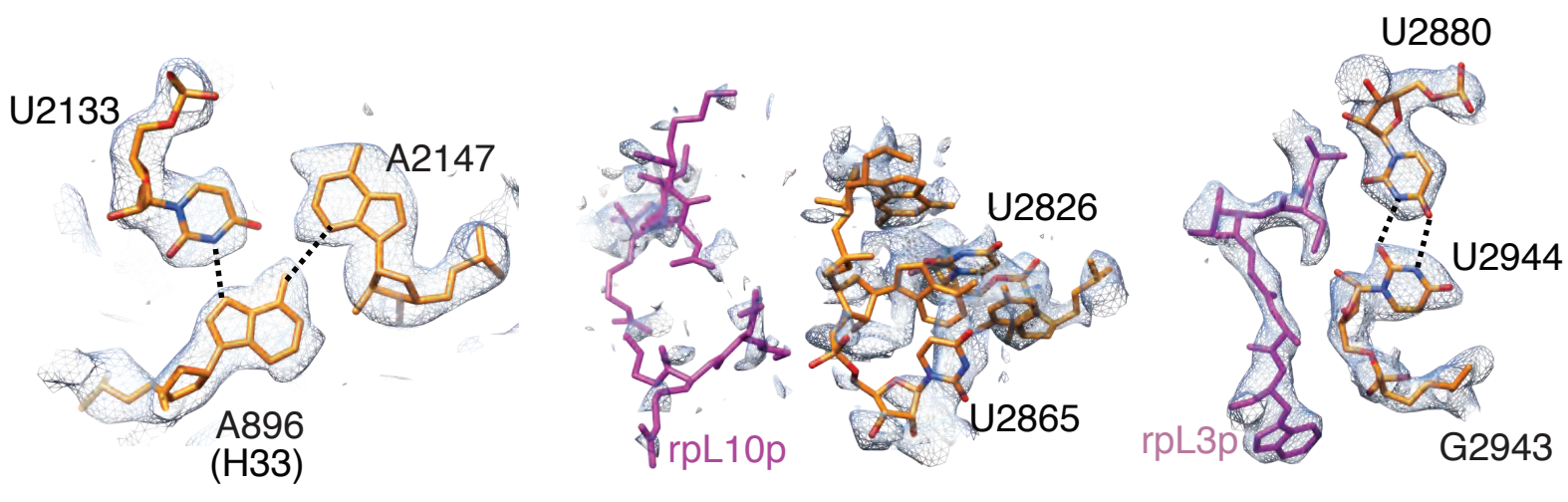

Supplementary Figure 8. The correspondng electron potential density maps in the cbf5D95A ribosome around the pseodouridine clusters on the large subunit shown in Figure 4C for nop1-D243A ribosome. 